This is a preprint of an article published by Elsevier . The final version of Sil Nevejans, Nicholas Ballard, Iván Rivilla, Mercedes Fernández, Antxon Santamaria, Bernd Reck, José M. Asua, Synthesis of mechanically strong waterborne poly(urethane-urea)s capable of self-healing at elevated temperatures, European Polymer Journal, (2019), 112, 411-422 is available at https://doi.org/10.1016/j.eurpolymj.2019.01.022

\title{
Synthesis of mechanically strong waterborne poly(urethane- urea)s capable of self-healing at elevated temperatures
}

\author{
Sil Nevejans, ${ }^{a, b}$ Nicholas Ballard, ${ }^{a}$ Iván Rivilla, ${ }^{c}$ Mercedes Fernández, ${ }^{a}$ Antxon Santamaria, ${ }^{a}$ Bernd \\ Reck, ${ }^{b}$ and José M. Asua ${ }^{a^{*}}$ \\ aPOLYMAT, University of the Basque Country UPV/EHU, Joxe Mari Korta Center, Avenida Tolosa \\ 72, 20018 Donostia-San Sebastián, Spain, E-mail: jm.asua@ehu.es \\ bDispersions and Colloidal Materials, BASF SE, 67056 Ludwigshafen, Germany \\ 'ORFEO-CINQA, University of the Basque Country UPV/EHU, Joxe Mari Korta Center, Avenida \\ Tolosa 72, 20018 Donostia-San Sebastián, Spain and Donostia International Physics Center \\ (DIPC), Po Manuel Lardizabal 3, 20018 Donostia-San Sebastián, Spain
}

\begin{abstract}
Although various chemistries have been introduced into polyurethanes in order to obtain self-healing abilities, implementing these materials in applications requiring high strength is challenging as strong materials imply a limited molecular motion, but without movement of polymer chains self-healing is not possible. Here, waterborne poly(urethane-urea)s $(\mathrm{PU}(\mathrm{U}) \mathrm{s})$ based on aromatic disulfide compounds are developed which balance these contradictory requirements by presenting good mechanical properties at room temperature, while showing the mobility necessary for healing when moderately heated. The influence of hard monomers on the stability and mobility of the materials is investigated by qualitative scratch closure and rheological measurements, so that the limits of the readily available aromatic disulfide compounds, bis(4-aminophenyl)- and bis(4hydroxyphenyl)disulfide, can be determined. Subsequently, a modified aromatic disulfide compound, bis[4-(3'-hydroxypropoxy)phenyl]disulfide, with increased reactivity, solubility and flexibility is synthesized and incorporated into the PU backbone, so that materials with more attractive mechanical properties, reaching ultimate tensile strengths up to $23 \mathrm{MPa}$, and self-healing abilities could be obtained.
\end{abstract}

Keywords: waterborne dispersion, poly(urethane-urea), aromatic disulfide, self-healing, dynamic bonds, mechanical strength

\section{Introduction}

Self-healing polymers have attracted a lot of attention over the last decades as they provide a potential solution for the persisting problem of material damage, enabling an extended product life-time..$^{1-10}$ Self-healing polymers which can heal intrinsically, making use of reversible chemical or physical bonds, are especially interesting for long-term use as they are able to undergo multiple healing events. ${ }^{11}$ Although various classes of polymer can be used to produce self-healing materials, segmented polyurethanes are perhaps the most attractive as they possess both a soft phase, which provides the mobility of the polymer chains that is necessary to enable healing, and a hard phase, which preserves the mechanical stability of the material. ${ }^{9}$ Furthermore, polyurethanes (PUs) have a built-in supramolecular healing ability due to the formation of $\mathrm{H}$-bonds between their backbones which provides the material with a basic level of intrinsic recovery upon damage. As 
polyurethanes are also very versatile materials which are able to incorporate various functional moieties, it is possible to implement additional chemistries into the PU in order to obtain an enhanced healing ability supplementary to the inherent $\mathrm{H}$-bonding. ${ }^{12}$

Among the broad range of chemistries that have already been introduced into PUs in order to obtain self-healing materials, ${ }^{13-19}$ disulfide bonds seem to be particularly interesting due to the fact that they are able to dynamically exchange when exposed to various stimuli, e.g. heat, light, redox or $\mathrm{pH}^{20}$ Several $\mathrm{PUs}$ have already been developed using the dynamic exchange of linear aliphatic disulfides in order to obtain self-healing materials under the influence of external stimuli.. ${ }^{21-28}$ However, by introducing an aromatic disulfide compound, bis(4-aminophenyl)disulfide $\left(\mathrm{S}_{2}\left(\mathrm{PhNH}_{2}\right)_{2}\right)$, Rekondo et al. were able to develop a cross-linked poly(urethane-urea) which was able to heal at room temperature without the use of any catalysts. ${ }^{29}$ They demonstrated that, unlike their aliphatic counterparts, aromatic disulfides could undergo exchange at room temperature, with later studies demonstrating that this exchange occurs via a radical intermediate..$^{20,30}$

The dynamic behaviour of the aromatic disulfide at reduced temperatures has subsequently been explored by several groups in the area of self-healing. ${ }^{31-33}$ For example, using the same disulfide Yang et al. synthesized a PU elastomer with improved tensile strength for which self-healing could be induced by heating to $60{ }^{\circ} \mathrm{C}$. They observed that for more cross-linked materials a higher tensile strength was obtained, but this occurred with a concomitant lowering of the ability to self-heal. ${ }^{34} \mathrm{Kim}$ et al. developed a thermoplastic polyurethane with an increased toughness by introducing an aromatic disulfide diol, bis(4-hydroxyphenyl)disulfide $\left(\mathrm{S}_{2}(\mathrm{PhOH})_{2}\right)$, which could also heal at room temperature. Using this system, they reported an ultimate tensile strength of $\pm 7 \mathrm{MPa}$, which is at the upper limit of the reported values for self-healing systems at room temperature. ${ }^{35}$

Although in many cases it is attractive to obtain self-healing at room temperature, this inherently demands a certain level of mobility of the polymer which compromises the mechanical properties and can lead to creep as well as a limited ability to withstand wear. ${ }^{36-38}$ This is a major issue in polyurethane materials as in many high-end applications the higher cost of polyurethanes is overlooked owing to their superior mechanical strength. For example, while there are a wide variety of polymers that are used in waterborne coatings, few can match polyurethane dispersions for applications requiring strong coatings such as furniture, automotive and floor coatings. As a result, the majority of applications of $\mathrm{PU}$ dispersions require high tensile strengths, typically exceeding 20 $\mathrm{MPa} .{ }^{39-42}$ This requirement for high tensile strength puts the constraints of commercial materials beyond the limits of current self-healing polymers.

To overcome this gap, in this work we seek to develop waterborne polymer dispersions which show sufficiently high mechanical resistance at room temperature and additionally recover from damage when chain mobility is induced by external stimuli such as heat. In order to meet this objective, the synthesis of waterborne poly(urethane-urea)s containing 
aromatic disulfide compounds is described. First, the influence of the hard 2,2bis(hydroxymethyl)propionic acid (DMPA) monomer, which acts as an internal ionic stabilizing agent upon neutralization in dispersion, on the self-healing ability of linear poly/urethane-urea)s (PUUs) is investigated via scratch closure and rheological measurements. Afterwards, the limits for solubility, reactivity and flexibility of the readily available aromatic disulfides, bis(4-aminophenyl)- and bis(4-hydroxyphenyl)-disulfide, in the synthesis of the waterborne $P U(U) s$ is tested. Finally, on the basis of these investigations, a structurally modified aromatic disulfide compound, bis[4-(3'hydroxypropyloxy)phenyl]disulfide $\left(\mathrm{S}_{2}\left(\mathrm{Ph}\left(\mathrm{CH}_{2}\right)_{3} \mathrm{OH}\right)_{2}\right)$, is synthesized and introduced to a higher extent into the polymer backbone so that a waterborne $\mathrm{PU}(\mathrm{U})$ material is developed with increased strength and mobility. Hence, incorporation of the modified aromatic disulfide compound enlarges the possibilities of developing more efficient self-healing polymers of interest for high-end applications.

\section{Experimental}

Materials

Acetone (Sigma-Aldrich, $\geq 99.5 \%)$, bis(4-aminophenyl)disulfide $\left(\mathrm{S}_{2}\left(\mathrm{PhNH}_{2}\right)_{2}, \mathrm{TCl},>98.0 \%\right)$, bis(4-hydroxyphenyl)disulfide $\left(\mathrm{S}_{2}(\mathrm{PhOH})_{2}, \mathrm{TCl},>98 \%\right), \quad 2,2$-bis(hydroxymethyl)propionic acid (DMPA, Sigma-Aldrich, 98\%) 3-bromo-1-propanol (Apollo Scientific, 96\%), bromophenol blue (Fluka), dibutyltin dilaurate (DBTL, Sigma-Aldrich, 95\%), diethylamine (DEA, Sigma-Aldrich, $\geq 99.5 \%$ ), ethyl acetate (EtOAc, ACROS Organics, $\geq 99.5 \%$ ), hexane (Fisher Chemicals, >99\%), hydrochloric acid $1 \mathrm{~N}$ ( $\mathrm{HCl}$, Panreac), isophorone diisocyanate (IPDI, Sigma-Aldrich, 98\%), methyl ethyl ketone (MEK, ACROS Organics, >99\%), polytetrahydrofuran (PolyTHF, BASF, $\left.2000 \mathrm{~g}^{\mathrm{mol}}{ }^{-1}\right)$, potassium carbonate $\left(\mathrm{K}_{2} \mathrm{CO}_{3}\right.$, SigmaAldrich, $\geq 99 \%$ ), sodium chloride ( $\mathrm{NaCl}$, Sigma-Aldrich, $\geq 99.5 \%)$, sodium sulfate $\left(\mathrm{Na}_{2} \mathrm{SO}_{4}\right.$, Sigma-Aldrich, $\geq 99 \%$ ), tetrahydrofuran (THF, Scharlab), triethylamine (TEA, ACROS Organics, 99\%) were used as received.

\section{Synthesis of bis[4-(3'-hydroxypropoxy)phenyl]disulfide $\left(\mathrm{S}_{2}\left(\mathrm{Ph}\left(\mathrm{CH}_{2}\right)_{3} \mathrm{OH}\right)_{2}\right)$}<smiles>Oc1ccc(SSc2ccc(O)cc2)cc1</smiles><smiles>OCCCBr</smiles>

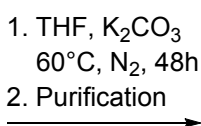

Figure 1. Claisen etherification to obtain bis[4-(3'-hydroxypropoxy)phenyl]disulfide.

Inspired by the synthetic method reported by Ohishi et al., ${ }^{43}$ a mixture of bis(4hydroxyphenyl)disulfide (100 g, $0.40 \mathrm{~mol})$, 3-bromo-1-propanol $(51 \mathrm{~mL}, 1.00 \mathrm{~mol})$ and potassium carbonate $(554 \mathrm{~g}, 4.01 \mathrm{~mol})$ in THF (100 wt\% of the solid reagents) as solvent was stirred at $60^{\circ} \mathrm{C}$ for $48 \mathrm{~h}$ under $\mathrm{N}_{2}$-atmosphere (Figure 1), in a jacketed glass reactor equipped with a mechanical stirrer and a condenser. Afterwards, the reaction mixture was filtered and washed with EtOAc. The obtained organic filtrate was washed with $1 \mathrm{~N} \mathrm{HCl}$ and brine, after which it was dried over anhydrous $\mathrm{Na}_{2} \mathrm{SO}_{4}$. The solvent was removed from the product under vacuum and the residue material was purified by recrystallization in an EtOAc:Hexane-mixture (3:5). Finally, the product was dried at $50^{\circ} \mathrm{C}$ under vacuum to give 
bis[4-(3'-hydroxypropyloxy)phenyl]disulfide

$\mathrm{S}_{2}\left(\mathrm{Ph}\left(\mathrm{CH}_{2}\right)_{3} \mathrm{OH}\right)_{2}$

[IUPAC:

((disulfanediylbis(4,1-phenylene))bis(oxy))bis(propan-1-ol)].

Yield: $70.5 \mathrm{~g}$ (64 mol\%). Pale yellow powder. FTIR (neat, $\left.\mathrm{cm}^{-1}\right): 3319.19,2945.40$, 2870.80, 1883.87, 1589.02. m.p.: $60.3-61.2^{\circ} \mathrm{C}$. ${ }^{1} \mathrm{H}$ NMR $(500 \mathrm{MHz}$, Chloroform-d) $\delta 7.44$ $-7.37(\mathrm{~d}, \mathrm{~J}=8.79 \mathrm{~Hz}, 2 \mathrm{H}), 6.89-6.82(\mathrm{~d}, \mathrm{~J}=8.80 \mathrm{~Hz}, 2 \mathrm{H}), 4.12(\mathrm{t}, J=6.0 \mathrm{~Hz}, 2 \mathrm{H}), 3.87$ $(\mathrm{t}, \mathrm{J}=5.9 \mathrm{~Hz}, 2 \mathrm{H}), 2.05(\mathrm{~m}, \mathrm{~J}=5.9 \mathrm{~Hz}, 2 \mathrm{H}), 1.81(\mathrm{~s}, 1 \mathrm{H}(\mathrm{OH})) .{ }^{13} \mathrm{C} \mathrm{NMR}(126 \mathrm{MHz}$, Chloroform-d) $\delta$ 159.31, 132.82, 128.77, 115.36, 77.50, 77.25, 76.99, 65.88, 60.40, 32.12. Anal. Calcd. for $\mathrm{C}_{18} \mathrm{H}_{22} \mathrm{O}_{4} \mathrm{~S}_{2}$ : C 58.99, H 6.05, S 17.50. Found: C 58.96, H 6.01, S 17.42. HRMS (ESI) for $\mathrm{C}_{18} \mathrm{H}_{22} \mathrm{O}_{4} \mathrm{~S}_{2}$ calculated $[\mathrm{M}+\mathrm{H}]^{+}:$366.0960. Found: 366.0960 .

\section{Synthesis of waterborne polyurethane-urea dispersions}

Synthesis of the waterborne PUU dispersions based on bis(4-aminophenyl)disulfide $\mathrm{S}_{2}\left(\mathrm{PhNH}_{2}\right)_{2}$

In order to obtain the prepolymer, PolyTHF $\left(M_{n}=2000\right.$ g.mol $\left.{ }^{-1}\right)$, DMPA and IPDI were fed together into a $100 \mathrm{~mL}$ jacketed glass reactor equipped with a mechanical stirrer and a condenser. Next, DBTL (0.2-0.4 wt\% of reactants) and acetone (45-60 wt \%) were added and the mixture was stirred for $2 \mathrm{~h}$ at $56^{\circ} \mathrm{C}$ under refluxing conditions. A first series of PUUs was prepared varying the amount of DMPA added to the reaction mixture from 3 to $7 \mathrm{wt} \%$ of reactants. The formulation for the syntheses of these different pre-polymers can be found in Table 1. After $2 \mathrm{~h}$, the isocyanate concentration had reduced to the theoretical level as determined by back titration and the mixture was cooled down to room temperature so that bis(4-aminodiphenyl)disulfide ( 0.33 eq. of IPDI) could be added into the vessel to react with the residual free NCO-groups of the prepolymer for $4 \mathrm{~h}$. Finally, the mixture was neutralized with TEA (100 mol\% of DMPA) after which deionized water (100$150 \mathrm{wt} \%$ ) was added dropwise to obtain a dispersion. Acetone was removed from the dispersion by evaporation using a rotary evaporator at 556 mbar so that a solids content of $30-35 \mathrm{wt} \%$ was obtained. A summary of the synthetic process is shown in Figure 2.

Table 1. Formulation of different PUU syntheses performed varying the amount of DMPA and bis(4-aminophenyl disulfide) (wt\% based on the total amount of reactants).

\begin{tabular}{|c|c|c|c|c|c|c|}
\hline Run & Sample & Unit & DMPA & IPDI & PolyTHF & $\mathrm{S}_{2}\left(\mathrm{PhNH}_{2}\right)_{2}$ \\
\hline \multirow{2}{*}{1} & \multirow{2}{*}{ PUU-3D-0.33S } & wt $\%$ & 3 & 19 & 71 & 7 \\
\hline & & eq. & 0.25 & 1 & 0.42 & 0.33 \\
\hline \multirow{2}{*}{2} & \multirow{2}{*}{ PUU-4D-0.33S } & wt $\%$ & 4 & 21 & 67 & 8 \\
\hline & & eq. & 0.31 & 1 & 0.36 & 0.33 \\
\hline \multirow{2}{*}{3} & \multirow{2}{*}{ PUU-5D-0.33S } & wt $\%$ & 5 & 22 & 64 & 8 \\
\hline & & eq. & 0.35 & 1 & 0.32 & 0.33 \\
\hline \multirow{2}{*}{4} & \multirow{2}{*}{ PUU-6D-0.33S } & wt $\%$ & 6 & 24 & 61 & 9 \\
\hline & & eq. & 0.38 & 1 & 0.28 & 0.33 \\
\hline \multirow{2}{*}{5} & \multirow{2}{*}{ PUU-7D-0.33S } & $w t \%$ & 7 & 26 & 57 & 10 \\
\hline & & eq. & 0.42 & 1 & 0.24 & 0.33 \\
\hline \multirow{2}{*}{6} & \multirow{2}{*}{ PUU-3D-0.44S } & wt $\%$ & 3 & 22 & 64 & 11 \\
\hline & & eq. & 0.23 & 1 & 0.33 & 0.44 \\
\hline \multirow{2}{*}{7} & \multirow{2}{*}{ PUU-3D-0.53S } & wt $\%$ & 3 & 24 & 58 & 14 \\
\hline & & eq. & 0.21 & 1 & 0.27 & 0.53 \\
\hline
\end{tabular}




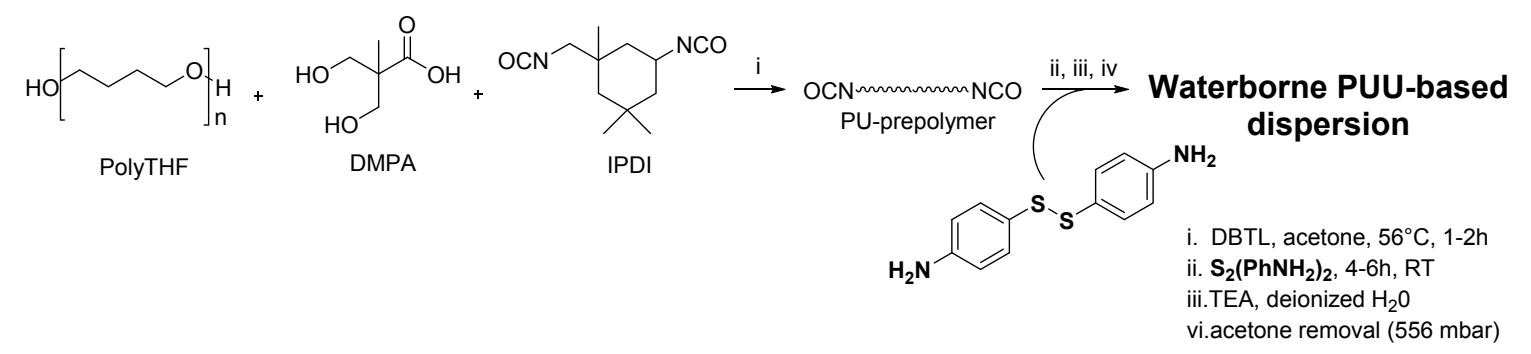

Figure 2. Synthetic procedure of waterborne PUU dispersions.

For the second series of PUUs based on $\mathrm{S}_{2}\left(\mathrm{PhNH}_{2}\right)_{2}$, a constant amount of DMPA was used (3 wt $\%$ of reactants), while a variable amount of bis(4-aminophenyl disulfide) was added to the prepolymer for incorporation into the PUU backbone as is depicted in Table 1. Due to the variable amount of disulfide and therefore varying necessity of free NCOgroups, the prepolymer reaction times were $2 \mathrm{~h}, 1.5 \mathrm{~h}$ and $1 \mathrm{~h}$ for PUU-3D-0.33S, PUU3D-0.44S and PUU-3D-0.53S, respectively. Subsequently, a reaction time of $6 \mathrm{~h}$ instead of $4 \mathrm{~h}$ was required for PUU-3D-0.44S and PUU-3D-0.53S to assure full incorporation of the larger amount of bis(4-aminophenyl disulfide) before neutralization, dispersion and evaporation could be carried out.

\section{Synthesis of the waterborne PU dispersion based on bis(4-hydroxyphenyl)disulfide}

PolyTHF (Mn=2000 g.mol-1 $, 8.40 \mathrm{~g}, 4.20 \mathrm{mmol})$, DMPA (1.16 g, $8.63 \mathrm{mmol})$, IPDI $(6.00 \mathrm{~g}$, $27.00 \mathrm{mmol}$ ) and bis(4-hydroxyphenyl)disulfide $(3.55 \mathrm{~g}, 14.18 \mathrm{mmol})$ were fed together into a $100 \mathrm{~mL}$ jacketed glass reactor equipped with a mechanical stirrer and a condenser. Next, DBTL ( $0.3 \mathrm{wt} \%$ of reactants) and MEK ( $\pm 55 \mathrm{wt} \%)$ were added into the vessel and the mixture was stirred for $60 \mathrm{~h}$ at $80^{\circ} \mathrm{C}$ under refluxing conditions. The mixture was cooled down to room temperature and neutralized with TEA $(1.20 \mathrm{~mL}, 8.63 \mathrm{mmol})$ after which deionized water (100 wt\%) was added dropwise to obtain a dispersion. MEK was removed from the dispersion by evaporation using a rotary evaporator at 243 mbar so that a solids content of $\pm 30 \mathrm{wt} \%$ was obtained.

Synthesis of the waterborne PU dispersions based on bis[4-(3' hydroxypropoxy) phenyl]disulfide $\left(\mathrm{S}_{2}\left(\mathrm{Ph}\left(\mathrm{CH}_{2}\right)_{3} \mathrm{OH}\right)_{2}\right)$

PolyTHF $\left(\mathrm{M}_{\mathrm{n}}=2000 \mathrm{~g}^{\mathrm{mol}}{ }^{-1}\right)$, DMPA, IPDI and bis[4-(3'-hydroxypropoxy)phenyl]disulfide $\left(\mathrm{S}_{2}\left(\mathrm{Ph}\left(\mathrm{CH}_{2}\right)_{3} \mathrm{OH}\right)_{2}\right)$ were fed together into a $100 \mathrm{~mL}$ jacketed glass reactor equipped with a mechanical stirrer and a condenser. Next, DBTL (0.3 wt\% of reactants) and MEK $( \pm 60$ wt $\%$ ) were added into the vessel and the mixture was stirred for $8 \mathrm{~h}$ at $80^{\circ} \mathrm{C}$ under refluxing conditions. The amount of DMPA added in the synthesis was constant (6 wt\% of reactants), while the amount of $\mathrm{S}_{2}\left(\mathrm{Ph}\left(\mathrm{CH}_{2}\right)_{3} \mathrm{OH}\right)_{2}$ was varied as shown in Table 2. Finally, the mixture was neutralized with TEA (100 mol\% of DMPA) after which deionized water (100 wt\%) was slowly added dropwise to obtain a dispersion. MEK was removed from the dispersion by evaporation using a rotary evaporator at 243 mbar so that a solids content of \pm 30 wt $\%$ was obtained. 
Table 2. Formulation of different PUs and PUUs based on bis[4-(3'hydroxypropoxy)phenyl]disulfide ( $w t \%$ based on the total amount of reactants).

\begin{tabular}{c|c|c|c|c|c|c}
\hline Run & Sample & Unit & DMPA & IPDI & PolyTHF & $\mathbf{S}_{2}\left(\mathbf{P h}\left(\mathrm{CH}_{2}\right)_{3} \mathrm{OH}\right)_{2}$ \\
\hline \multirow{2}{*}{$\mathbf{8}$} & \multirow{2}{*}{ PU-6D-0.33S } & wt\% & 6 & 25 & 54 & $\mathbf{1 4}$ \\
& & eq. & 0.42 & 1 & 0.24 & $\mathbf{0 . 3 3}$ \\
\hline \multirow{2}{*}{$\mathbf{9}$} & \multirow{2}{*}{ PU-6D-0.44S } & wt\% & 6 & 27 & 46 & $\mathbf{2 0}$ \\
& & eq. & 0.37 & 1 & 0.19 & $\mathbf{0 . 4 4}$ \\
\hline \multirow{2}{*}{$\mathbf{1 0}$} & \multirow{2}{*}{ PU-6D-0.53S } & wt\% & 6 & 30 & 38 & $\mathbf{2 6}$ \\
& & eq. & 0.33 & 1 & 0.14 & $\mathbf{0 . 5 3}$ \\
\hline
\end{tabular}

Synthesis of the waterborne PUU dispersion containing both bis(4-aminophenyl)disulfide and bis[4-(3'-hydroxypropoxy)phenyl]disulfide

The dispersion termed PUU-6D-0.53S-MIXED was obtained by first feeding PolyTHF $\left(\mathrm{M}_{\mathrm{n}}=2000 \mathrm{~g} \mathrm{~mol}^{-1}, 5.30 \mathrm{~g}, 2.65 \mathrm{mmol}\right)$, DMPA (0.79 g, $\left.5.90 \mathrm{mmol}\right)$, IPDI $(4.00 \mathrm{~g}, 18.00$ $\mathrm{mmol}$ ) and bis[4-(3'-hydroxypropoxy)phenyl]disulfide $(2.08 \mathrm{~g}, 5.67 \mathrm{mmol})$ together into a $100 \mathrm{~mL}$ jacketed glass reactor equipped with a mechanical stirrer and a condenser. Next, DBTL ( $0.3 \mathrm{wt} \%$ of reactants) and MEK ( $\pm 60 \mathrm{wt} \%)$ were added into the vessel and the mixture was stirred for $3 \mathrm{~h}$ at $80^{\circ} \mathrm{C}$ under refluxing conditions. Afterwards, the mixture was cooled down to room temperature and bis(4-aminodiphenyl)disulfide $(0.94 \mathrm{~g}, 3.78 \mathrm{mmol})$ was added into the vessel to react with the residual free NCO-groups of the prepolymer for $6 \mathrm{~h}$. Finally, the mixture was neutralized with TEA $(0.82 \mathrm{~mL}, 5.90 \mathrm{mmol})$ after which deionized water (100 wt\%) was slowly added dropwise to obtain a dispersion. MEK was removed from the dispersion by evaporation using a rotary evaporator at 243 mbar so that a solid content of \pm 30 wt $\%$ was obtained.

\section{$\underline{\text { Characterization }}$}

Infrared spectra were recorded on an FT-IR spectrometer (Bruker). All melting points were determined in a Büchi Melting Point B-540. The NMR spectra were recorded at $500 \mathrm{MHz}$ for ${ }^{1} \mathrm{H}-\mathrm{NMR}$, and $126 \mathrm{MHz}$ for ${ }^{13} \mathrm{C}\{\mathrm{H}\}-\mathrm{NMR}$ in $\mathrm{CDCl}_{3}$ at room temperature. The data are reported as $\mathrm{s}=$ singlet, $\mathrm{d}=$ doublet, $\mathrm{t}=$ triplet, $\mathrm{m}=$ multiplet, coupling constant(s) in $\mathrm{Hz}$, integration. Elemental analysis was carried out using a TruSpec Micro (LECO) analyzer. HRMS-analysis was performed with an LC/Q-TOF with Agilent Jet Stream ESI ionization source.

To determine the NCO content of the PU prepolymer, a back titration of the excess of diethylamine (DEA) molecules, which were added to neutralize the free NCO-groups of the $\mathrm{PU}$, with $\mathrm{HCl}$ was performed. ${ }^{44,45}$ The Z-average diameter of the polymer particles was measured by dynamic light scattering (DLS) using a Malvern Zetasizer Nano ZS (Malvern Instruments). Samples were prepared by diluting a fraction of the latex with deionized water, and the analyses were carried out at $25^{\circ} \mathrm{C}$. The molecular weight of the dried films dissolved in THF was determined by Size Exclusion Chromatography/Gel Permeation 
Chromatography (SEC/GPC). The instrument consisted of a pump (LC-20A, Shimadzu), an autosampler (Waters 717), a differential refractometer (Waters 2410), a UV detector measuring at 262nm (Waters 2487) and three columns in series (Styragel HR2, HR4 and HR6, with pore sizes ranging from 102-106 $\AA$ ). Chromatograms were obtained at $35^{\circ} \mathrm{C}$ using a THF flow rate of $1 \mathrm{~mL}$. $\mathrm{min}^{-1}$. A series of polystyrene (PS) standards in the range of 580-3 848000 g.mol$^{-1}$ were used to obtain the calibration curve which provided molecular weights of the polymer relative to polystyrene.

Films with a final thickness of $0.50-0.75 \mathrm{~mm}$ were obtained by casting the dispersion in silicon molds $(25 \times 55 \mathrm{~mm})$. The casted films were first dried for 1 day at $23^{\circ} \mathrm{C}$ and subsequently for 3 days at $60^{\circ} \mathrm{C}$ after which they were equilibrated for 3 days at $23^{\circ} \mathrm{C}$ while maintaining $55 \% \mathrm{RH}$. Dynamic mechanical analysis (DMA) measurements were carried out in a Triton 2000 DMA (Triton Technology) or on a TA Instruments DMA Q800 (only for sample PUU-6D-0.53S-MIXED) equipped with a liquid nitrogen cooling system. The measurements were performed in tension mode at a single frequency of $1 \mathrm{~Hz}$. The samples were cooled down to $\approx-150{ }^{\circ} \mathrm{C}$ and heated with a rate of $4{ }^{\circ} \mathrm{C} \cdot \mathrm{min}^{-1}$ till the temperature at which the minimum dynamic force of $0.01 \mathrm{~N}$ was hit. Stress-strain measurements were carried out on dumbbell type specimen under controlled conditions $\left(23^{\circ} \mathrm{C}\right.$ and $\left.55 \% \mathrm{RH}\right)$ on a tensile apparatus (Stable Micro System TA HD Plus Texture Analyzer) with a crosshead velocity of $25 \mathrm{~mm} \mathrm{~min}^{-1}$. For each experiment, the average of 3-6 replicate measurements is reported. For the scratch closure experiments, scratches were made with a depth of $\pm 75 \%$ of the thickness $( \pm 0.7 \mathrm{~mm})$ of the films using a razor blade with a thickness of $0.40 \mathrm{~mm}$ and subsequently closure at $80^{\circ} \mathrm{C}$ was followed using an optical microscope (Nikon Eclipse LV100ND). The rheological data were obtained from a strain-controlled Anton Paar Physica MCR101 rheometer using cone-plate geometry (cone $\varnothing=8 \mathrm{~mm}$, disk-shaped specimens: $\pm 10 \mathrm{~mm}$ in diameter and $0.50-0.75 \mathrm{~mm}$ in thickness). Frequency sweeps $(0.001-20 \mathrm{~Hz})$ at a strain of $0.5 \%$ were conducted at fixed temperatures ranging from $50-120^{\circ} \mathrm{C}$.

\section{Results and discussion}

Waterborne PU(U) dispersions based on diamine-terminated bis(4aminophenyl)disulfide

A series of poly(urethane-urea) dispersions containing varying amounts of bis(4aminophenyl)disulfide $\left(\mathrm{S}_{2}\left(\mathrm{PhNH}_{2}\right)_{2}\right)$ and the DMPA were synthesized using the formulations described in Table 1 and the process outlined in Figure 2. Through the variation of DMPA and aromatic disulfide content, the objective was to explore the balance between material strength and chain mobility in order to obtain mechanically strong selfhealing polymers. In a first set of experiments (Runs 1-5, Table 1), the amount of IPDI and disulfide compound was kept constant, while the DMPA content varied from 3 to $7 \mathrm{wt} \%$. In a second set of experiments (Runs 1, 6 and 7), the amount of IPDI and DMPA was kept constant, but here the amount of bis(4-aminophenyl)disulfide varied from 7 to $14 \mathrm{wt} \%$. 
In agreement with the function of DMPA as ionic stabilizer, Table 3 shows that the particle sizes $\left(d_{p}\right)$ of dispersions decreased when the amount of DMPA increased. In contrast, when the amount of the disulfide compound was increased the particle size increased significantly and broad particle size distributions were obtained. It is noteworthy to mention that, due to the high amount of disulfide compound added for the synthesis of PUU-D3$0.53 \mathrm{~S}$, the prepolymer was no longer a homogeneous solution but a highly viscous and optically turbid mass, which may explain the large particle sizes. The presence of large particles additionally led to sedimentation of PUU-3D-0.44S and PUU-3D-0.53S (Series 6 and 7). The characteristics of the waterborne PUU dispersions are also reflected in the films formed after casting the dispersions, as can be seen in Figure 3. PUU-3D-0.33S yielded a rather transparent and homogeneous film, while PUU-3D-0.44S showed a more turbid film and PUU-3D-0.53S formed an even more turbid and inhomogeneous film. This puts a limit on the amount of disulfide compound that can be introduced into the system, since unfavorable dispersions and film characteristics are obtained for too high levels of self-healing agent.

Table 3. Dispersion and polymer characteristics of PUUs based on $\mathbf{S}_{2}\left(\mathrm{PhNH}_{2}\right)_{2}$.

\begin{tabular}{c|c|c|c|c|c|c}
\hline \multirow{2}{*}{ Run } & \multirow{2}{*}{ Sample } & \multicolumn{2}{|c|}{ DLS measurement } & \multicolumn{3}{c}{ GPC measurement (RI) } \\
\cline { 3 - 7 } & & $\mathbf{d}_{\mathbf{p}} \mathbf{( n m )}$ & PDI & $\mathbf{M}_{\mathbf{n}} \mathbf{( k D a )}$ & $\mathbf{M}_{\mathbf{w}}(\mathbf{k D a})$ & $\mathbf{\Xi}$ \\
\hline $\mathbf{1}$ & PUU-3D-0.33S & 125 & 0.07 & 18 & 34 & 1.9 \\
$\mathbf{2}$ & PUU-4D-0.33S & 71 & 0.06 & 16 & 33 & 2.0 \\
$\mathbf{3}$ & PUU-5D-0.33S & 55 & 0.07 & 15 & 27 & 1.8 \\
$\mathbf{4}$ & PUU-6D-0.33S & 47 & 0.10 & 14 & 26 & 1.9 \\
$\mathbf{5}$ & PUU-7D-0.33S & 42 & 0.10 & 12 & 21 & 1.7 \\
\hline $\mathbf{6}$ & PUU-3D-0.44S & 260 & 0.80 & 11 & 23 & 2.0 \\
$\mathbf{7}$ & PUU-3D-0.53S & 520 & 0.83 & 8 & 16 & 2.0 \\
\hline
\end{tabular}

PUU-3D-0.33S

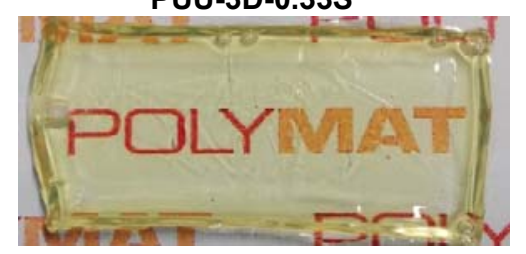

PUU-3D-0.44S

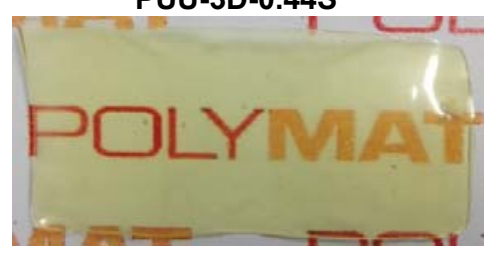

PUU-3D-0.53S

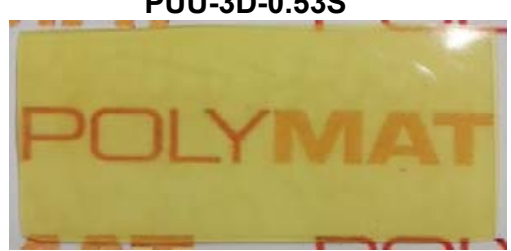

Figure 3. Films cast from dispersions with an increasing disulfide $\mathrm{S}_{2}\left(\mathrm{PhNH}_{2}\right)_{2}$ content.

When looking at the molecular weights $\left(M_{w}\right)$ shown in Table 3 , it can be noted that the $M_{w}$ decreased with DMPA. This was due to the fact that when keeping the level of IPDI/ $\mathrm{S}_{2}\left(\mathrm{PhNH}_{2}\right)_{2}$ constant, an increase of DMPA inevitably means a decrease of the macrodiol PolyTHF, and therefore lower molecular weights at similar degree of polymerization were obtained. Similarly, the values obtained for the molecular weights of the PUUs with a variable amount of disulfide compound, show that the $M_{w}$ decreased drastically with increasing disulfide content, although in this case the decrease was significantly greater. Moreover, the molecular weight distributions of these PUUs showed the presence of low molecular weight polymer in the case of PUU-3D-0.53S (Figure 4). The lower molecular weight PUU chains were most probably a result of a less effective 
incorporation of the disulfide compound due to the solubility problems observed at high concentrations of disulfide. Moreover, while PUU-3D-0.33S and PUU-3D-0.44S had almost complete incorporation of the disulfide, from the molecular weight distribution obtained by GPC using an UV absorption detector, it could be calculated that PUU-3D$0.53 \mathrm{~S}$ still had $2.5 \%$ of unreacted disulfide compound with respect to the total amount of disulfide added. As a result the degree of conversion was lower and therefore a lower $\mathrm{M}_{\mathrm{w}}$ of the polymer was observed.

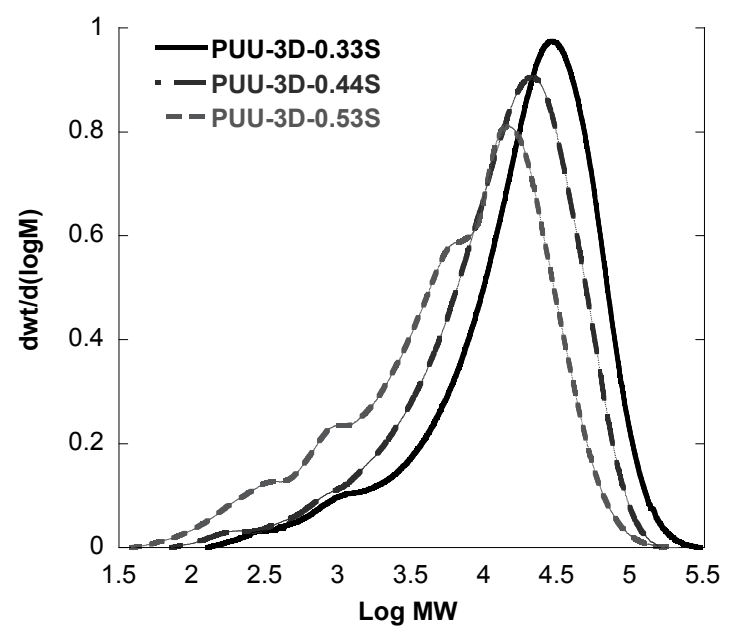

Figure 4. Molecular weight distribution obtained by GPC (RI) of the PUUs with variable amount of $\mathrm{S}_{2}\left(\mathrm{PhNH}_{2}\right)_{2}$.

The dynamic mechanical properties of the PUUs were analyzed by DMA (Figures 5 and 6 ). It is noteworthy to mention that a peak can be observed for the curves of the loss modulus at the lowest temperatures, around $-140^{\circ} \mathrm{C}$. Such a relaxation at low temperatures in the glassy state of the PUUs is comparable to the ones which have already been described in literature for bisphenol A polycarbonate and can therefore be linked to secondary relaxation processes due to the presence of closely interconnected aromatic rings, in this case linked through dynamic disulfide bonds. ${ }^{46,47}$ The most obvious relaxation, located around $-70^{\circ} \mathrm{C}$ for all the samples, is linked to the glass transition temperature of PolyTHF $\left(T_{g}=-77^{\circ} \mathrm{C}\right)$. At high temperatures, a broad relaxation is observed for PUU-5D-0.33S, PUU-6D-0.33S and PUU-7D-0.33S, which can reflect segmental motions of the hard parts of the PUUs. This high temperature relaxation shifts to higher temperatures with the amount of DMPA (Figure 5) or disulfide content (Figure 6), i.e. as the amount of soft PolyTHF is reduced and the number of hard units increased. Since the high temperatures relaxation is not observed for PUU-3D-0.33S and PUU-4D-0.33S, it can be deduced that a minimum of hard units of PUU is necessary for this relaxation. This had a relevant influence on the overall mechanical properties of the samples, because the presence of organized hard units also provoked a considerable increase of the storage modulus E', in particular close to room temperature. Moreover, as can be seen in Figures 5 and $6, E^{\prime}$ decreases severely with temperature above the $T_{g}$ of $-70^{\circ} \mathrm{C}$ in the case of PUU-3D-0.33S and PUU-4D-0.33S, which is due to the absence of organized hard units in these samples. 


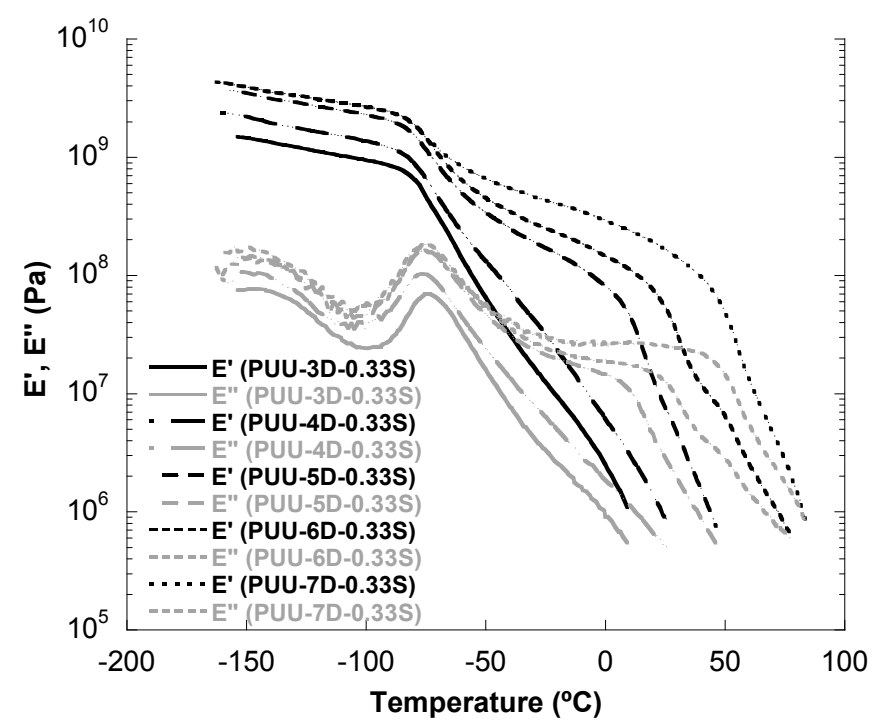

Figure 5. DMA results of PUUs based on a varying DMPA content.

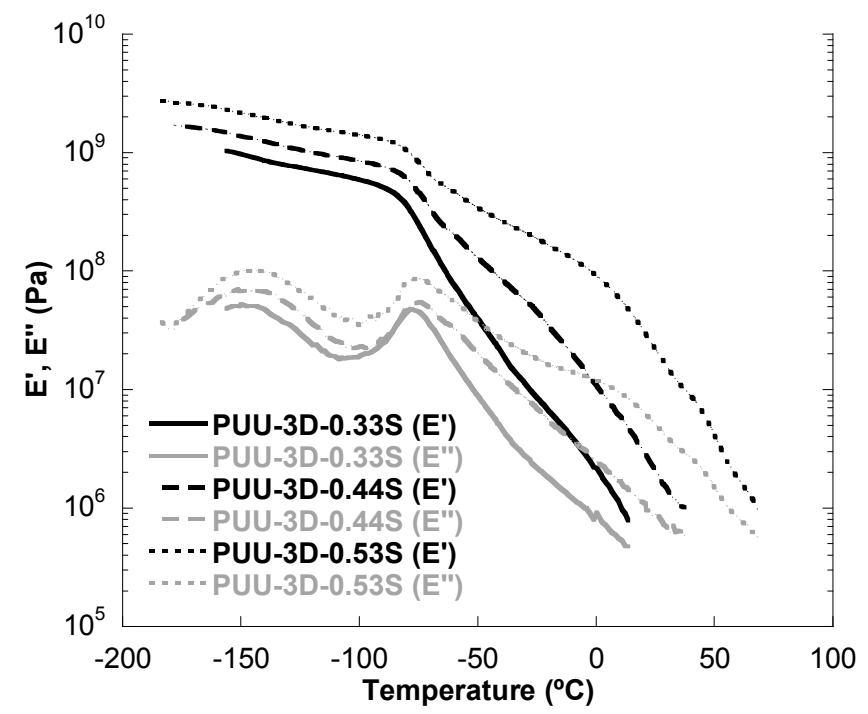

Figure 6. DMA results of PUUs based on a varying $\mathrm{S}_{2}\left(\mathrm{PhNH}_{2}\right)_{2}$ content.

Tensile test results obtained at room temperature were also affected by the presence of hard units. Table 4 and Figure 7 show that increasing the amount of DMPA or disulfide in the PUU backbone led to an enhancement of both the Young's modulus and ultimate tensile strength (UTS). The unexpected lower tensile strength for the PUU-7D-0.33S (Figure 7A) might be explained either by the lower $M_{w}$ of the material compared to the other PUUs or alternatively due to the higher $\mathrm{T}_{g}$ of the material (Figure 5) which could lead to a restricted film formation. It is noteworthy to mention that the values obtained for the tensile strength of these PUUs are significantly higher (UTS $\approx 17 \mathrm{MPa}$ at a strain rate of 25 $\left.\mathrm{mm} \cdot \mathrm{min}^{-1}\right)$ than those obtained for self-healing elastomers based on bis(4aminophenyl)disulfide (UTS $\approx 0.8 \mathrm{MPa}$ at $500 \mathrm{~mm} \cdot \mathrm{min}^{-1}$ ), ${ }^{29}$ and for waterborne organicinorganic hybrids with the same self-healing agent (UTS $\approx 4.5 \mathrm{MPa}$ at $20 \mathrm{~mm} \cdot \mathrm{min}^{-1}$ ). ${ }^{31}$ 
Even when comparing with values of the "tough" self-healing polyurethane elastomers reported previously (UTS $\approx 7.7 \mathrm{MPa}$ at $500 \mathrm{~mm} \cdot \mathrm{min}^{-1}$ and $6.8 \mathrm{MPa}$ at $100 \mathrm{~mm} \cdot \mathrm{min}^{-1}$ ), ${ }^{34,35}$ it can be concluded that the PUUs presented here are significantly stronger materials, especially considering the low strain rate at which the tensile tests were performed.
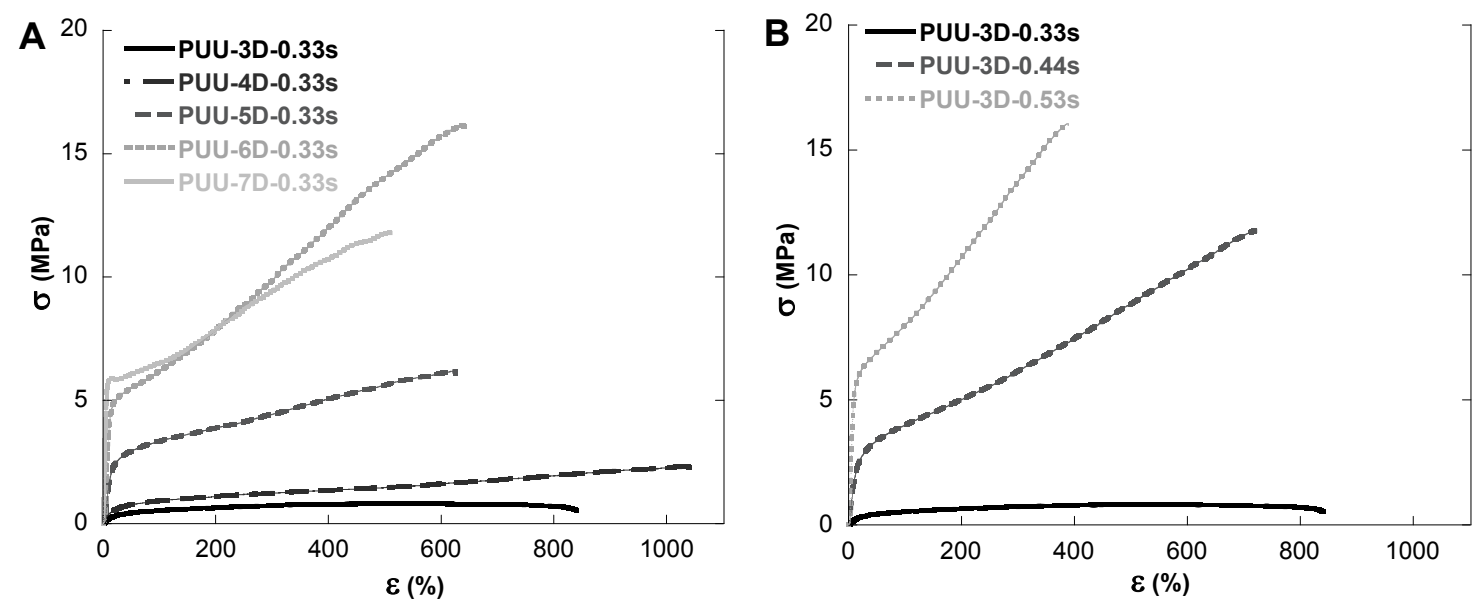

Figure 7. Stress-strain $(\sigma-\varepsilon)$ curves of PUUs with varying DMPA (A) and disulfide (B) content.

Table 4. Tensile testing results of PUUs with varying DMPA and disulfide content.

\begin{tabular}{c|c|c|c|c}
\hline Run & Sample & Young's modulus (MPa) & UTS (MPa) & $\boldsymbol{\varepsilon}_{\mathbf{f}}(\boldsymbol{\%})$ \\
\hline $\mathbf{1}$ & PUU-3D-0.33S & $2.7 \pm 0.3$ & $0.9 \pm 0.1$ & $850 \pm 10$ \\
$\mathbf{2}$ & PUU-4D-0.33S & $5.0 \pm 0.6$ & $2.4 \pm 0.5$ & $970 \pm 110$ \\
$\mathbf{3}$ & PUU-5D-0.33S & $26.2 \pm 1.8$ & $6.3 \pm 0.3$ & $610 \pm 20$ \\
$\mathbf{4}$ & PUU-6D-0.33S & $85.8 \pm 2.6$ & $16.5 \pm 0.2$ & $680 \pm 30$ \\
$\mathbf{5}$ & PUU-7D-0.33S & $141.5 \pm 4.2$ & $11.3 \pm 0.3$ & $470 \pm 20$ \\
\hline $\mathbf{6}$ & PUU-3D-0.44S & $33.0 \pm 1.1$ & $11.3 \pm 0.4$ & $680 \pm 25$ \\
$\mathbf{7}$ & PUU-3D-0.53S & $128.0 \pm 2.8$ & $16.7 \pm 0.5$ & $400 \pm 15$ \\
\hline
\end{tabular}

Although for coating applications damage resistance and therefore strength is required, the polymer chains still need to show some mobility in order to repair the damage and allow recovery of broken bonds and interactions. As a qualitative method to check the overall mobility of the chains, the scratch closure of the PUUs was optically monitored. In order to reach the terminal or flow zone of the viscoelastic response, and so induce chain mobility, the films were heated up to a temperature of $80^{\circ} \mathrm{C}$, well above the glass transition temperature of all the samples. Figure 8 shows that increasing the amount of DMPA, scratch closure was slower, because the material became stiffer as reflected by the higher values of E' (Figure 5) and Young modulus (Figure 7A). An increase in disulfide content, that also provided polymers with higher rigidity, led to the same effect in scratch closure (Figure 9). It is worth emphasizing that these results show that self-healing is the result of the interplay between rheology and bond exchange and that for self-healing agents that affect both characteristics, the use of higher quantities of the self-healing agent may have a negative effect on the healing process. 


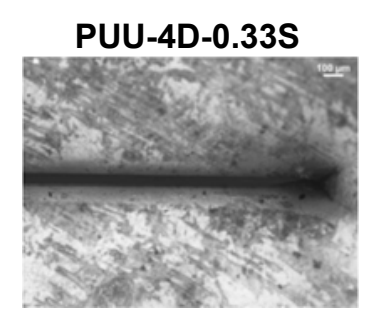

$\downarrow 1 \mathrm{~d}$

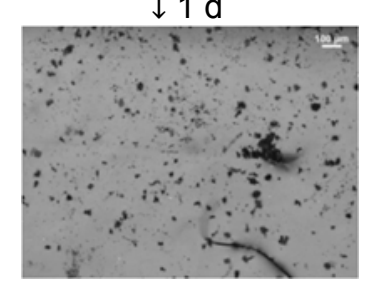

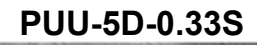

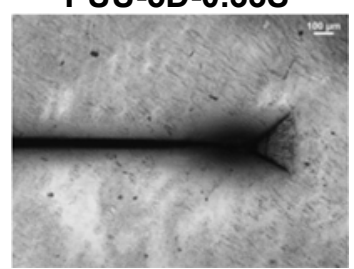

$\downarrow 1 \mathrm{~d}$

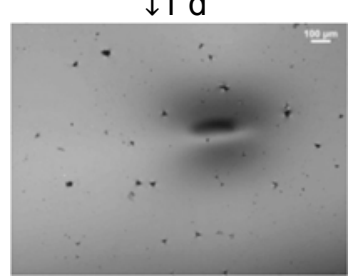

PUU-6D-0.33S

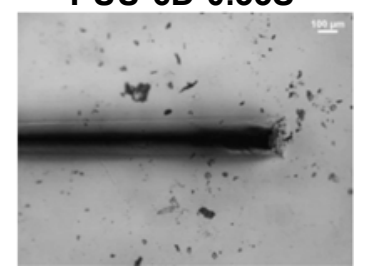

$\downarrow 2 \mathrm{~d}$

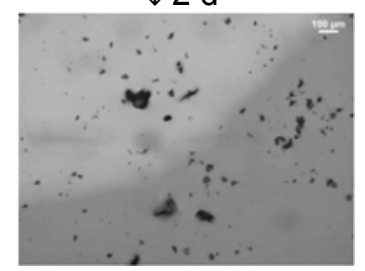

PUU-7D-0.33S

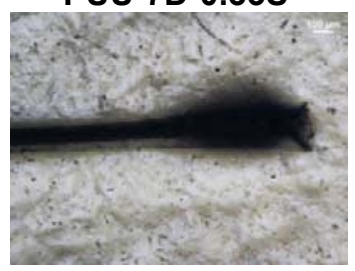

$\downarrow 7 \mathrm{~d}$

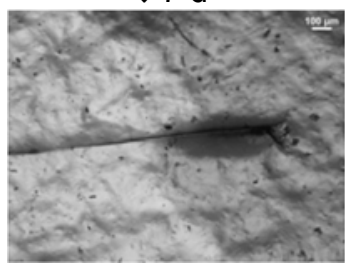

Figure 8. Scratch closure at $80^{\circ} \mathrm{C}$ of $\mathrm{PUUs}$ based on $\mathrm{S}_{2}\left(\mathrm{PhNH}_{2}\right)_{2}$ with varying DMPA content.

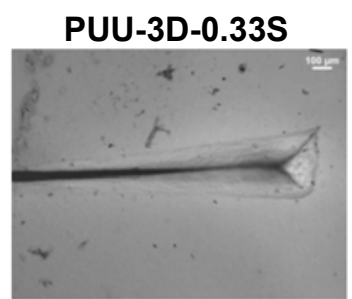

$\downarrow 2 \mathrm{~h}$

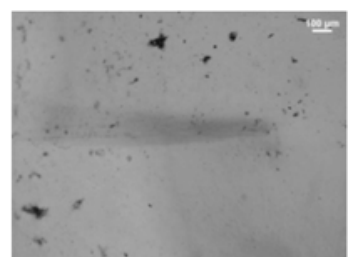

PUU-3D-0.44S

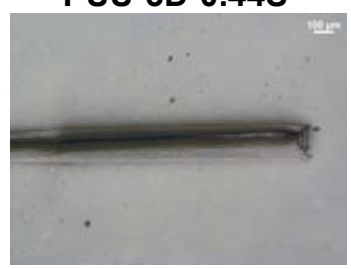

$\downarrow 1 \mathrm{~d}$

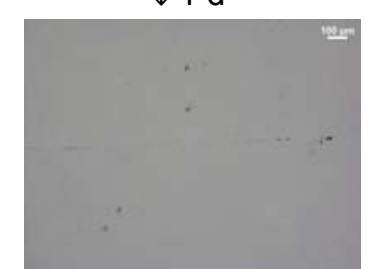

PUU-3D-0.53S

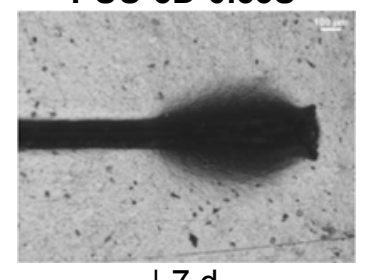

$\downarrow 7 \mathrm{~d}$

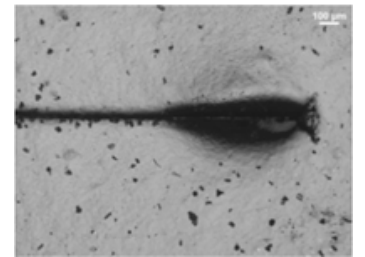

Figure 9. Scratch closure at $80^{\circ} \mathrm{C}$ of $\mathrm{PUUs}$ based on a varying amount of $\mathrm{S}_{\mathbf{2}}\left(\mathrm{PhNH}_{2}\right)_{2}$.

The scratch closure measurements demonstrated that a certain degree of chain mobility is generated in these rather stiff materials. Contrary to the local or segmental motions, the global mobility of the chains is only detected in the terminal viscoelastic zone, at which parameters involving large scale motions can be measured. A representative parameter of the mobility of the chains is the so-called terminal relaxation time $\left(\tau_{d}\right)$, that for a given temperature is the inverse of the frequency $\left(\omega_{d}=1 / \tau_{d}\right)$ at which the crossover between the storage (G') and the loss (G') moduli occurs. ${ }^{48-51}$ Figure 10 presents the master curves of $G^{\prime}$ and $G^{\prime \prime}$ at a reference temperature of $80^{\circ} \mathrm{C}$. In order to obtain these curves, the viscoelastic behaviour of the polymers was studied by performing frequency sweep measurements at temperatures ranging from 50 to $120^{\circ} \mathrm{C}$ and afterwards applying the time-temperature superposition (TTS) principle. This principle is only valid for materials that do not change their microstructure upon exposure to temperature, which is not always the case for polymers based on dynamic bonds. ${ }^{52-61} \mathrm{~A}$ way to verify if the TTS principle is applicable is using the van-Gurp-Palmen-plot (vGP-plot), in which the phase angle $\delta$ of the measured rheological data is depicted versus the corresponding absolute value of the complex shear modulus $\left|G^{*}\right|$. If the isothermal frequency curves merge into a common line, the principle holds. ${ }^{62}$ For all polymers in Table 3 (varying amount of DMPA or disulfide), a 
good overlap of these different curves was obtained (Figures S5 and S6 in the Supplementary Information), which shows that the TTS principle is applicable for these materials, at least for temperatures above the high temperature relaxation (Figures 5 and 6 ) associated to the hard units of the PUUs.

The relaxation times $\left(\tau_{d}\right)$ of the different PUUs presented in Table 5 follow the same trend as the scratch closure times with the harder materials presenting the longer relaxation times. However, comparison with the results in Figures 8 and 9 shows that the times required for scratch closure were much longer than the relaxation times. Likely the different time scales are due to the fact that scratch closure requires the creep deformation of the polymer over relatively large times, which is a complex viscoelastic process that implies a spectrum of retardation times. ${ }^{52}$
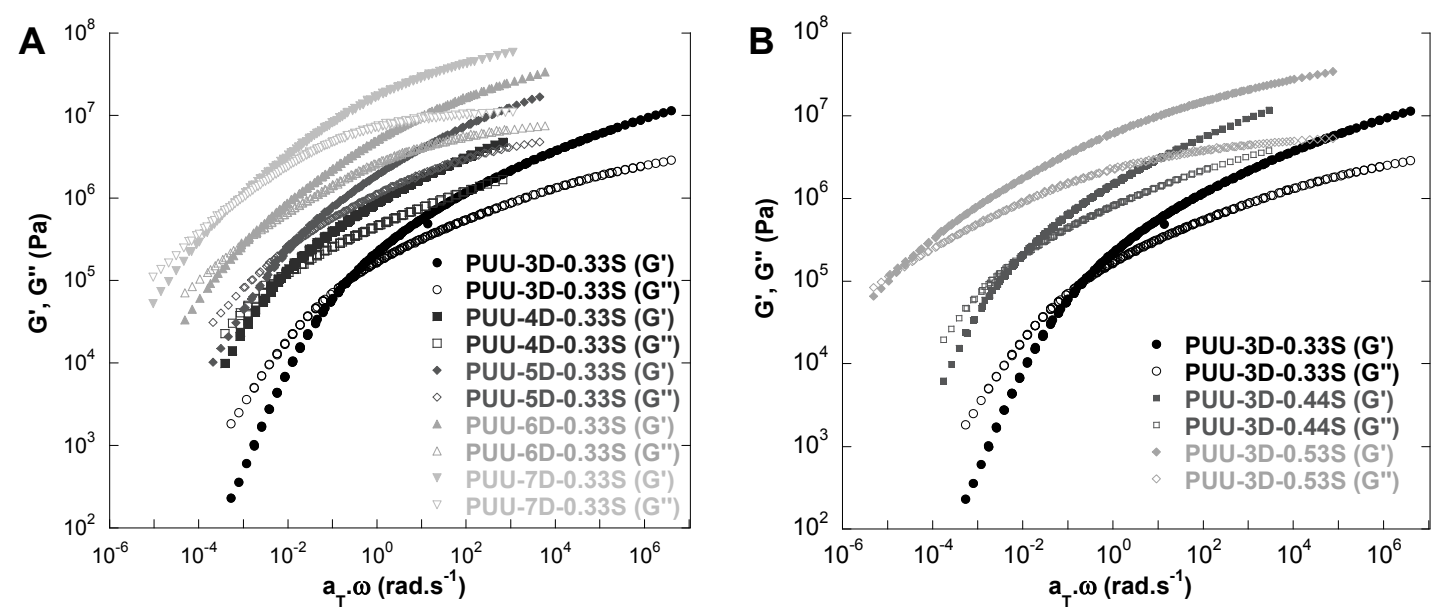

Figure 10. Master curves $\left(\mathrm{T}_{\text {ref }}=80^{\circ} \mathrm{C}\right)$ for the PUUs based on $\mathrm{S}_{2}\left(\mathrm{PhNH}_{2}\right)_{2}$ with varying DMPA (A) and disulfide content (B) obtained by applying TTS using horizontal shift factors (аT).

Table 5. Characteristic values for G'-G" crossover in the master curves $\left(T_{\text {ref }}=80^{\circ} \mathrm{C}\right)$ of PUUs based on $\mathrm{S}_{2}\left(\mathrm{PhNH}_{2}\right)_{2}$ with varying amount of DMPA and disulfide.

\begin{tabular}{c|c|c|c}
\hline Run & Sample & $\omega_{d}\left(\right.$ rad. $\left.^{-1}\right)$ & $\tau_{\mathbf{d}}$ \\
\hline $\mathbf{1}$ & PUU-3D-0.33S & 0.2315 & $30 \mathrm{~s}$ \\
$\mathbf{2}$ & PUU-4D-0.33S & 0.0062 & $17 \mathrm{~min}$ \\
$\mathbf{3}$ & PUU-5D-0.33S & 0.0089 & $12 \mathrm{~min}$ \\
$\mathbf{4}$ & PUU-6D-0.33S & 0.0013 & $1.5 \mathrm{~h}$ \\
$\mathbf{5}$ & PUU-7D-0.33S & 0.0005 & $3.5 \mathrm{~h}$ \\
\hline $\mathbf{6}$ & PUU-3D-0.44S & 0.0082 & $13 \mathrm{~min}$ \\
$\mathbf{7}$ & PUU-3D-0.53S & 0.00001 & $7 \mathrm{~d}$ \\
\hline
\end{tabular}

It is clear from the preceding that the use of bis(4-aminophenyl)disulfide presents a number of issues. First, due to the relatively low solubility in the polymerization reaction, the amount of bis(4-aminophenyl)disulfide that can be incorporated is limited, influencing the $M_{w}$ of the PUU that can be obtained. Furthermore, a significant increase in bis(4aminophenyl)disulfide renders the PUU dispersion instable. In addition, increasing the amount of self-healing agent in the PUU backbone makes the material stiffer limiting its mobility which hampers self-healing. Therefore, there is a need for alternative self-healing 
agents that still contain reactive aromatic disulfides, but that additionally provide enough flexibility so the self-healing ability is not hindered by the rigidity of the material.

\section{Waterborne PU(U) dispersions based on diol-terminated disulfide compounds}

In the search for other aromatic disulfide compounds, the commercially available bis(4hydroxyphenyl)disulfide was considered as an interesting alternative. Due to the lower reactivity of alcohols towards isocyanates, the reaction was performed at $80^{\circ} \mathrm{C}$ using MEK as solvent. However, even at the high reaction temperature and with the prolonged reaction times $(60 \mathrm{~h})$, more than $15 \%$ of the bis(4-hydroxyphenyl)disulfide was not incorporated into the PU-backbone, as shown by the molecular weight distribution obtained by GPC using an UV absorption detector in Figure S7 (Supplementary Information). This incomplete incorporation was due to the fact that the reactivity of phenolic $\mathrm{OH}$-groups towards isocyanates is significantly lower than that of water. ${ }^{63,64}$

Since the commercially available diamine- and diol-terminated disulfides showed the aforementioned problems, bis[4-(3'-hydroxypropoxy)phenyl]disulfide $\left(\mathrm{S}_{2}\left(\mathrm{Ph}\left(\mathrm{CH}_{2}\right)_{3} \mathrm{OH}\right)_{2}\right.$, Figure 1) was synthesized. The reactivity of the primary alcohols was expected to increase sufficiently so that full incorporation of the self-healing agent would be possible in acceptable reaction times. Moreover, by introducing an alkyl chain consisting of 3 carbon atoms onto the aromatic rings, the flexibility of alkyl chain can counteract the rigid aromatic rings of the disulfide compound and therefore a more mobile polymer was anticipated. Additionally, the alkyl chain would also increase the solubility of the polymer in the reaction mixture, providing the opportunity to increase the disulfide content into the PU-backbone without encountering solubility issues. Advantageously, bis[4-(3'-hydroxypropoxy)phenyl]disulfide was added to the reactor together with the other diols (DMPA and PolyTHF) reacting together in one step to form a polyurethane (PU) (Figure 11) in MEK at $80^{\circ} \mathrm{C}$. After that, the waterborne PU dispersion could be obtained through neutralization with TEA and addition of deionized water.

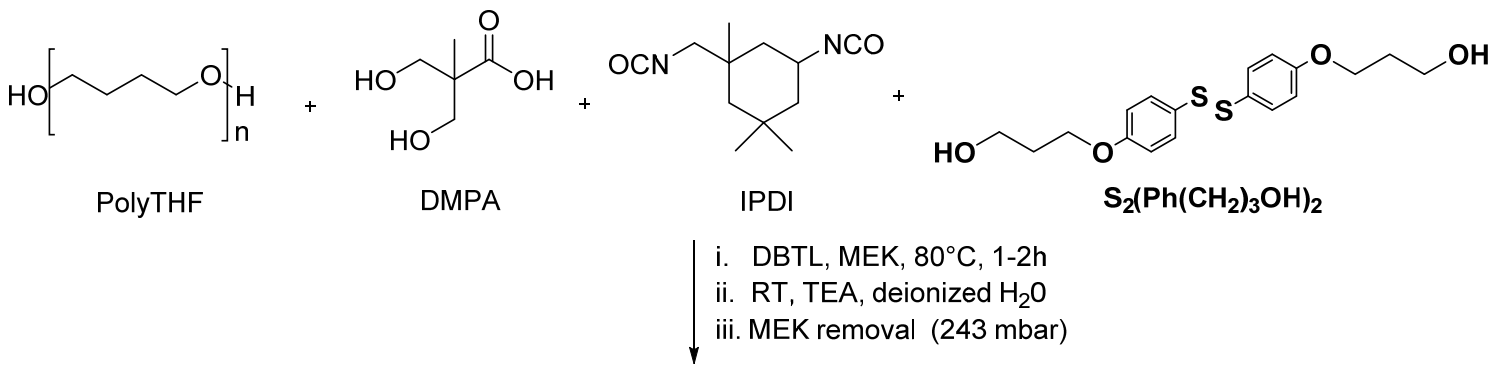

\section{Waterborne PU dispersion}

Figure 11. Scheme of synthesis procedure of waterborne PU dispersion.

For the series of PUs synthesized by introducing $\mathrm{S}_{2}\left(\mathrm{Ph}\left(\mathrm{CH}_{2}\right)_{3} \mathrm{OH}\right)_{2}$, the amount of IPDI and the DMPA content (6 wt\%) were kept constant. The higher DMPA content was used so that the polymer had acceptable rigidity for coating applications. The amount of $\mathrm{S}_{2}\left(\mathrm{Ph}\left(\mathrm{CH}_{2}\right)_{3} \mathrm{OH}\right)_{2}$ varied from 0.33 eq. of IPDI (14 wt\%) for PU-6D-0.33S and 0.44 eq. of 
IPDI (20 wt\%) for PU-6D-0.44S to a maximum of 0.53 eq. of IPDI (26 wt\%) for PU-6D$0.53 \mathrm{~S}$ (Table 2). For the same number of molar equivalents, the weight fraction of $\mathrm{S}_{2}\left(\mathrm{Ph}\left(\mathrm{CH}_{2}\right)_{3} \mathrm{OH}\right)_{2}$ was higher than in the previous cases due to the higher molecular weight. Unlike the aromatic diamine disulfide, during the synthesis of the series of PUs with increasing amounts of $\mathrm{S}_{2}\left(\mathrm{Ph}\left(\mathrm{CH}_{2}\right)_{3} \mathrm{OH}\right)_{2}$, no solubility issues of the polymer in the solvent were observed. Additionally, a mixed disulfide polymer, PUU-6D-0.53S-MIXED, was synthesized by introducing both $\mathrm{S}_{2}\left(\mathrm{Ph}\left(\mathrm{CH}_{2}\right)_{3} \mathrm{OH}\right)_{2}$ and $\mathrm{S}_{2}\left(\mathrm{PhNH}_{2}\right)_{2}$ as self-healing agents into the PUU backbone. The formulation of the mixed disulfide polymer was chosen with the intention that the amounts of IPDI, PolyTHF and DMPA were similar to the amounts used in the synthesis of PU-6D-0.53S, described in detail in the experimental section of this work, so that direct comparison of PU-6D-0.53S with PUU-6D-0.53S-MIXED was possible.

For all PUs and the mixed disulfide polymer (PUU-6D-0.53S-MIXED) nearly complete incorporation of disulfide compound was obtained even for the highest disulfide content. In addition, stable dispersions of small particle size and relatively narrow PDI were obtained (Table 6). The films cast from the PU dispersions were transparent and almost colourless (Figure 12) even though the amount of disulfide was substantially higher than that used for the PUUs that yielded yellowish films (Figure 3). Homogeneous and transparent films were also obtained for PUU-6D-0.53S-MIXED, although the presence of $\mathrm{S}_{2}\left(\mathrm{PhNH}_{2}\right)_{2}$ made the film colour slightly more yellow (Figure 12).

Table 6. Dispersion and polymer characteristics of $\mathrm{PUs}$ and $\mathrm{PUUs}$ based on $\mathrm{S}_{2}\left(\mathrm{Ph}\left(\mathrm{CH}_{2}\right)_{3} \mathrm{OH}\right)_{2}$.

\begin{tabular}{c|c|c|c|c|c|c}
\hline \multirow{2}{*}{ Run } & \multirow{2}{*}{ Sample } & \multicolumn{2}{|c|}{ DLS measurement } & \multicolumn{3}{c}{ GPC measurement (RI) } \\
\cline { 2 - 7 } & & $\mathbf{d}_{\mathbf{p}} \mathbf{( n m )}$ & PDI & $\mathbf{M}_{\mathbf{n}} \mathbf{( k D a )}$ & $\mathbf{M}_{\mathbf{w}}(\mathbf{k D a})$ & $\mathbf{\Xi}$ \\
\hline $\mathbf{4}$ & PUU-6D-0.33S & 47 & 0.10 & 14 & 26 & 1.9 \\
\hline $\mathbf{8}$ & PU-6D-0.33S & 35 & 0.18 & 11 & 22 & 1.9 \\
$\mathbf{9}$ & PU-6D-0.44S & 32 & 0.15 & 13 & 23 & 1.8 \\
$\mathbf{1 0}$ & PU-6D-0.53S & 36 & 0.14 & 11 & 27 & 2.4 \\
\hline $\mathbf{1 1}$ & PUU-6D-0.53S-MIXED & 50 & 0.11 & 14 & 26 & 1.8 \\
\hline
\end{tabular}

PU-6D-0.33S

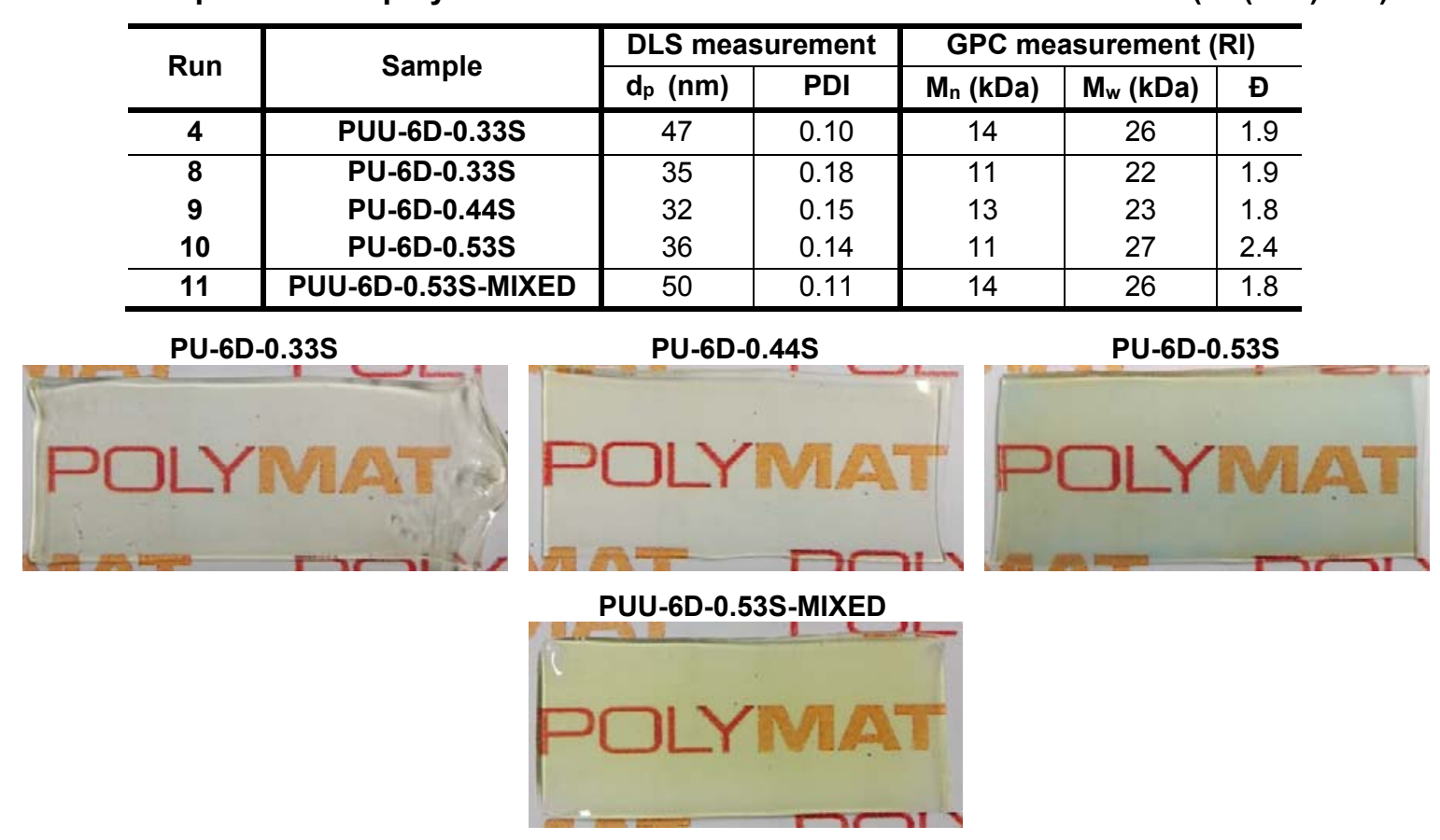

PU-6D-0.44S

PUU-6D-0.53S-MIXED
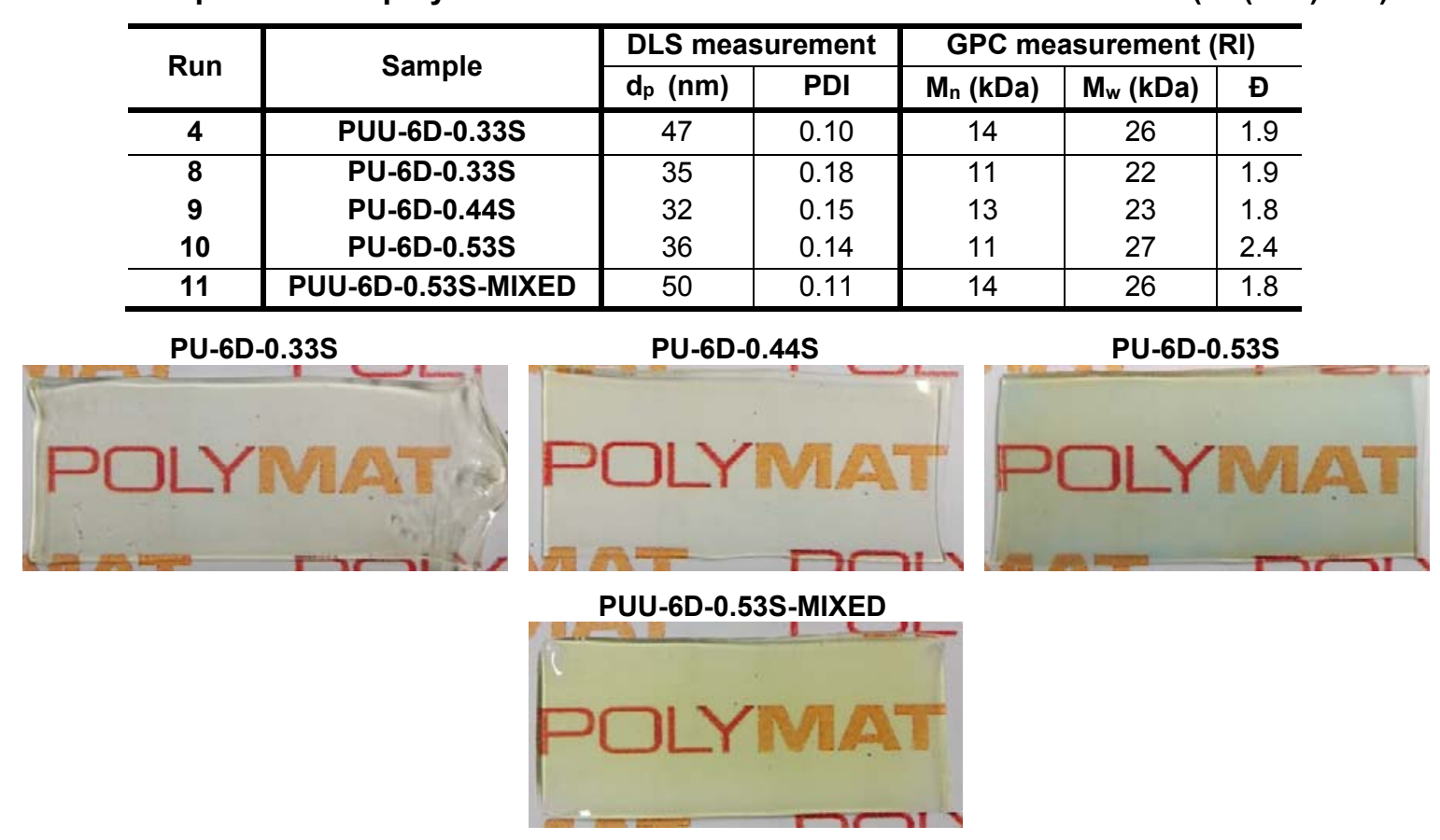

PU-6D-0.53S

.

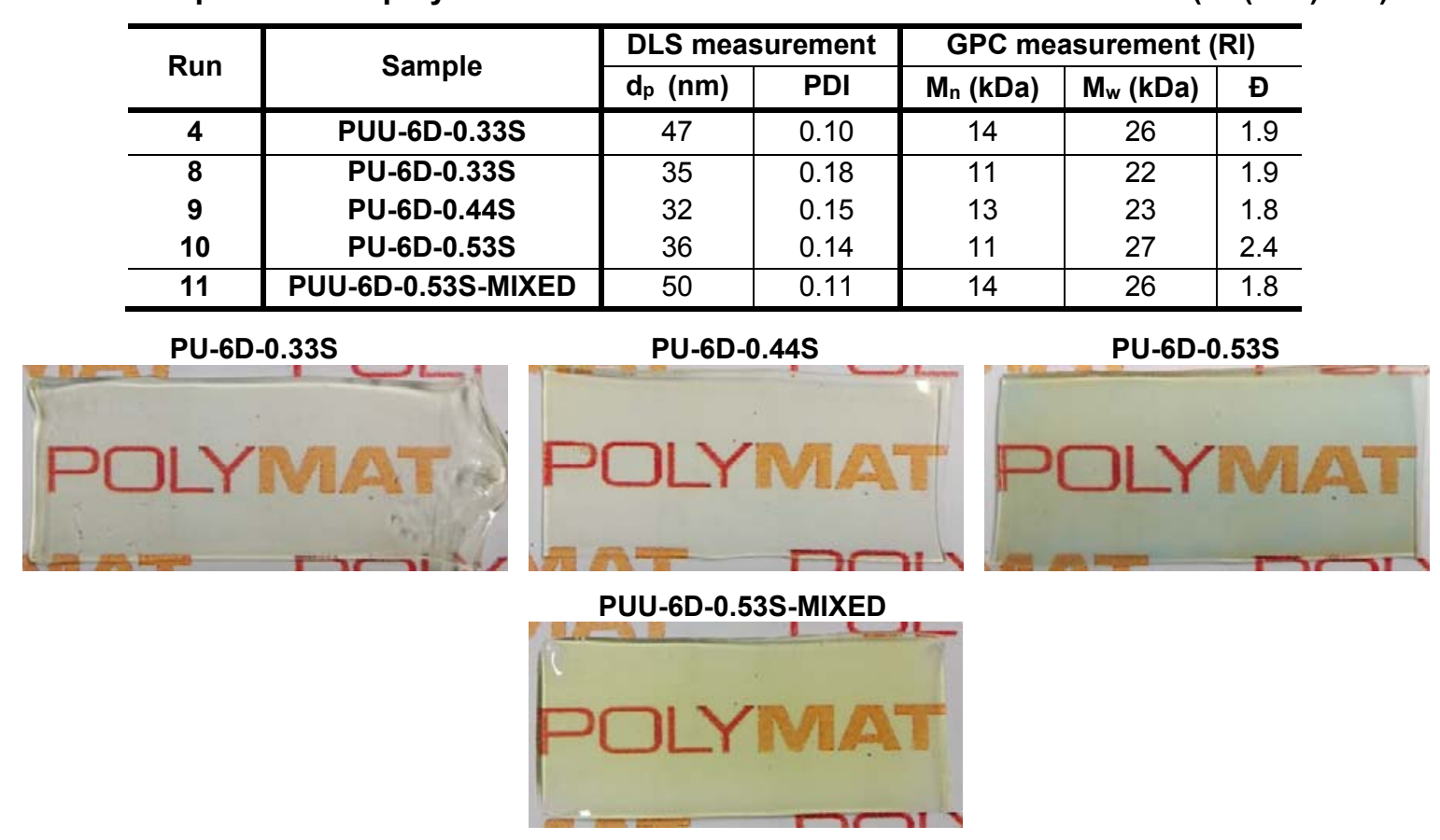

Figure 12. Films from dispersions $\mathrm{PUs}$ based on $\mathrm{S}_{2}\left(\mathrm{Ph}\left(\mathrm{CH}_{2}\right)_{3} \mathrm{OH}\right)_{2}$ and $\mathrm{PUU}-6 \mathrm{D}-0.53 \mathrm{~S}-\mathrm{MIXED}$. 
The molecular weights obtained for the PUs were similar to that of PUU-6D-0.33S (Table 6). Moreover, on the contrary to what was observed for the PUUs, the $M_{w}$ of the polymer did not decrease with the amount of disulfide. The dynamic mechanical properties of the PU series were analyzed by DMA (Figure 13). As for the PUUs reported above, the secondary relaxation of closely interconnected aromatic rings led to a peak in E" modulus at around $-140^{\circ} \mathrm{C}$. Similar to the PUUs reported above, a low temperature $T_{g}$ was observed at $-70^{\circ} \mathrm{C}$ in all samples and a broad relaxation, which probably reflects segmental motions of the hard units of the system, was observed at temperatures close to room temperature. As could be expected, with increasing amounts of the aromatic disulfide the glass transition temperature was shifted to higher values. Therefore, the general interpretation of the results of Figure 13 is the same as those of Figure 5. However, the values obtained for the PUs were lower than those of PUU-6D-0.33S, due to the introduction of a more flexible self-healing agent into the polymer backbone and the absence of urea groups that reduced hydrogen bonding, which in turn decreased the rigidity of the PUs compared to the PUUs.

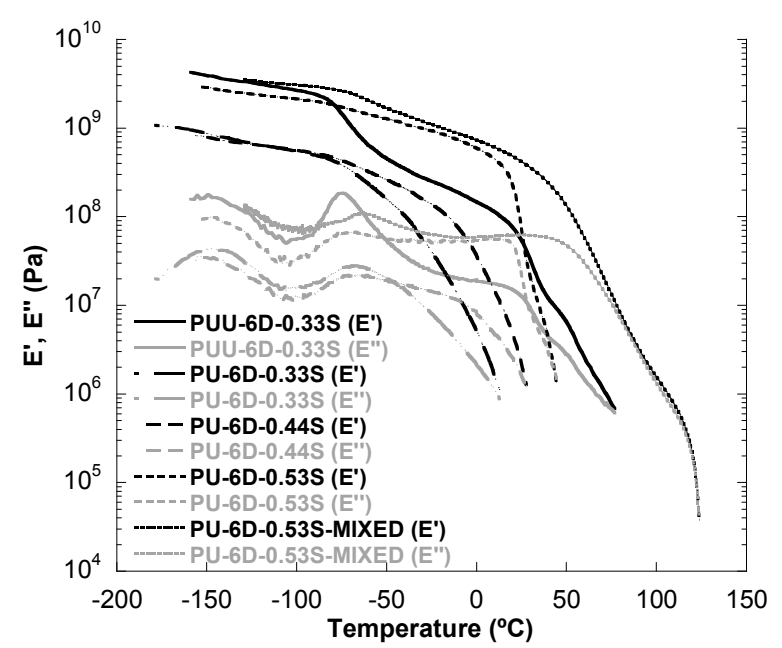

Figure 13. DMA results of $\mathrm{PU}(\mathrm{U}) \mathrm{s}$ based on a varying $\mathrm{S}_{2}\left(\mathrm{Ph}\left(\mathrm{CH}_{2}\right)_{3} \mathrm{OH}\right)_{2}$ content.

The results obtained from the tensile tests are presented in Figure 14 and Table 7. It can be seen that the Young's modulus and the ultimate tensile strength (UTS) increased, and the elongation at break $\left(\varepsilon_{\mathrm{f}}\right)$ decreased with the $\mathrm{S}_{2}\left(\mathrm{Ph}\left(\mathrm{CH}_{2}\right)_{3} \mathrm{OH}\right)_{2}$ content. The PUs show a more ductile behaviour after reaching a yield point in which the stress does not increase above the yield strength anymore. When replacing $21 \mathrm{~mol} \%$ of $\mathrm{S}_{2}\left(\mathrm{Ph}\left(\mathrm{CH}_{2}\right)_{3} \mathrm{OH}\right)_{2}$ by $\mathrm{S}_{2}\left(\mathrm{PhNH}_{2}\right)_{2}$ (PUU-6D-0.53S-MIXED), a significant increase of the Young's modulus and ultimate tensile strength was obtained compared to PU-6D-0.53S, although the measured strain was similar for both materials. This highlights the effect of the flexibility offered by the alkyl chain on the aromatic rings of the PUs and that of the urea groups. These effects are also evident when all these polymers are compared with PUU-6D-0.33S which displays a strong and non ductile behaviour without a significant yield point. 
Table 7. Tensile testing results of $\mathrm{PU}(\mathrm{U})$ s based on variable amount of $\mathrm{S}_{2}\left(\mathrm{Ph}\left(\mathrm{CH}_{2}\right)_{3} \mathrm{OH}\right)_{2}$.

\begin{tabular}{c|c|c|c|c}
\hline Run & Sample & Young's modulus (MPa) & UTS (MPa) & $\boldsymbol{\varepsilon}_{\mathbf{f}}(\%)$ \\
\hline $\mathbf{4}$ & PUU-6D-0.33S & $85.8 \pm 2.6$ & $16.5 \pm 0.2$ & $680 \pm 30$ \\
\hline $\mathbf{8}$ & PU-6D-0.33S & $2.8 \pm 0.4$ & $0.3 \pm 0.1$ & $520 \pm 35$ \\
$\mathbf{9}$ & PU-6D-0.44S & $53.0 \pm 3.8$ & $2.3 \pm 0.1$ & $385 \pm 10$ \\
$\mathbf{1 0}$ & PU-6D-0.53S & $321.0 \pm 7.8$ & $10.2 \pm 0.2$ & $210 \pm 10$ \\
\hline $\mathbf{1 1}$ & PUU-6D-0.53S-MIXED & $577.4 \pm 11.4$ & $23.1 \pm 0.5$ & $260 \pm 10$ \\
\hline
\end{tabular}

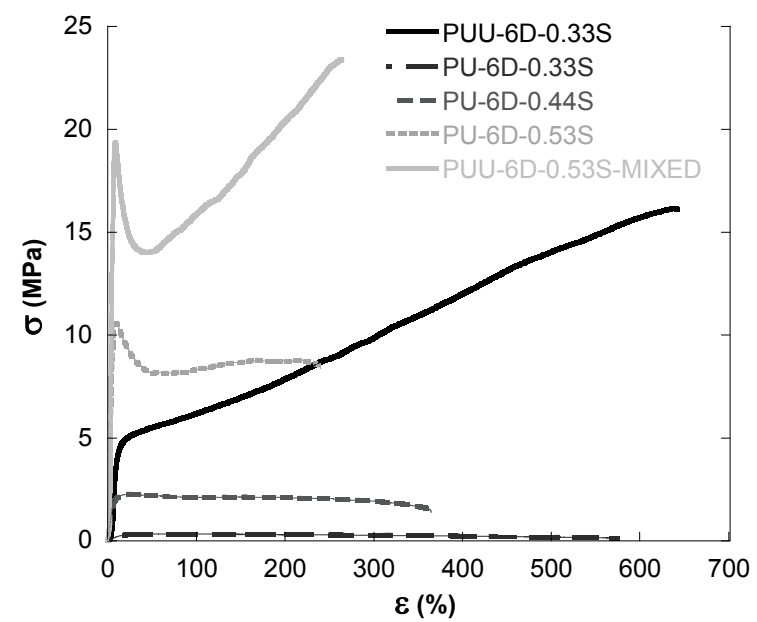

Figure 14. Stress-strain $(\sigma-\varepsilon)$ curves of $\mathrm{PU}(\mathrm{U})$ s based on varying $\mathrm{S}_{2}\left(\mathrm{Ph}\left(\mathrm{CH}_{2}\right)_{3} \mathrm{OH}\right)_{2}$ content.

Figure 15 presents the master curves of G' and G" at a reference temperature of $80^{\circ} \mathrm{C}$ of the polymers based on a variable amount of $\mathrm{S}_{2}\left(\mathrm{Ph}\left(\mathrm{CH}_{2}\right)_{3} \mathrm{OH}\right)_{2}$ in comparison with PUU$6 \mathrm{D}-0.33 \mathrm{~S}$. These curves were obtained from frequency sweep measurements carried out at different temperatures using the TTS principle. In this case, however, the van-GurpPalmen-plots did not merge to a single line (Figure S8) indicating that the materials showed some local change with temperature. This behavior was not unexpected, since the dynamic disulfide bonds can be activated at higher temperatures and therefore would give rise to a change in the microstructure. The reason why this effect appears for these materials, but could not be observed for the PUUs based on $\mathrm{S}_{2}\left(\mathrm{PhNH}_{2}\right)_{2}$, could possibly be explained by the fact that $\mathrm{S}_{2}\left(\mathrm{Ph}\left(\mathrm{CH}_{2}\right)_{3} \mathrm{OH}\right)_{2}$ generated a softer PU backbone where the dynamic disulfide exchange can act more freely than in the more rigid PUU backbone where additionally $\mathrm{H}$-bonds between the urea groups physically cross-link the material and further lock the ability of the disulfide bonds to exchange. Although the TTS principle does not hold as strongly as for the PUUs based on $\mathrm{S}_{2}\left(\mathrm{PhNH}_{2}\right)_{2}$, using both horizontal $\left(\mathrm{a}_{\mathrm{T}}\right)$ and vertical shift factors $\left(b_{T}\right)$ acceptable superposition could be achieved to obtain the master curves in Figure 15 . The relaxation times $\left(\tau_{d}\right)$ calculated from the crossover points in Figure 15 are presented in Table 8 . It can be seen that the relaxation time increases with the $\mathrm{S}_{2}\left(\mathrm{Ph}\left(\mathrm{CH}_{2}\right)_{3} \mathrm{OH}\right)_{2}$ content because the polymer becomes stiffer. Similarly, the incorporation of $\mathrm{S}_{2}\left(\mathrm{PhNH}_{2}\right)_{2}$ in the PUU-6D-0.53S-MIXED resulted in a further increase of the relaxation time. The broader crossover region observed in PUU-6D-0.53S-MIXED was attributed to the fact that a less homogeneous polymer was obtained as two different aromatic disulfide compounds were introduced into the PUU-backbone which broadens the time frame at which the different segments of the polymer relaxed. Nevertheless, for 
the considerably stiffer PUU-6D-0.53S-MIXED, the frequency at which G' and G" start crossing over is higher than for PUU-6D-0.33S, indicating a higher molecular mobility for some part of the polymer. However, for PUU-6D-0.53S-MIXED to start flowing completely, almost the same relaxation time $\left(\tau_{d}\right)$ has to be considered as PUU-6D-0.33S (Table 8).

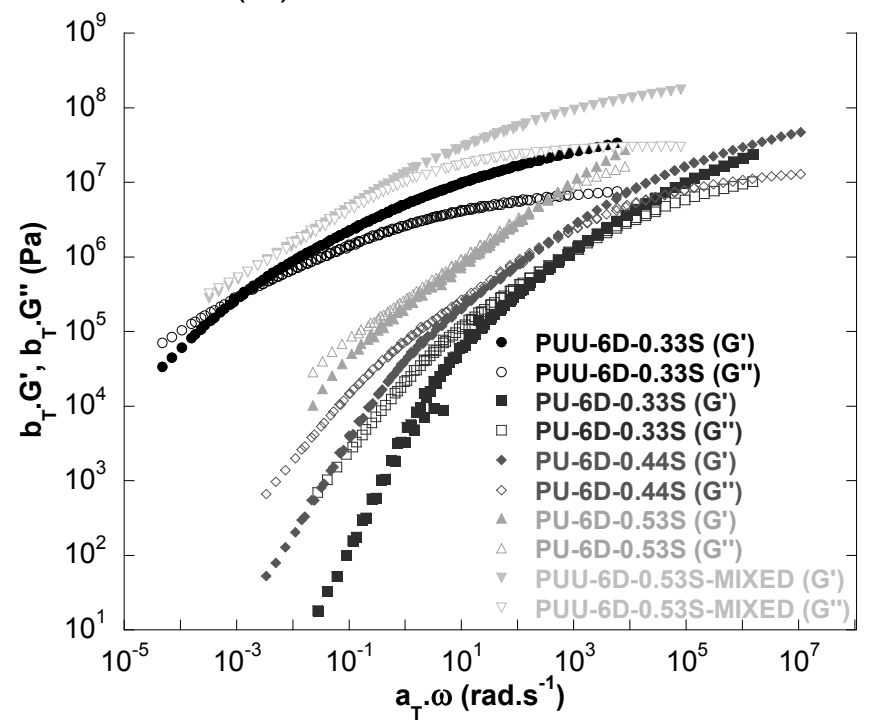

Figure 15. Master curves $\left(\mathrm{T}_{\text {ref }}=80^{\circ} \mathrm{C}\right)$ of $\mathrm{PU}(\mathrm{U}) \mathrm{s}$ based on varying $\mathrm{S}_{\mathbf{2}}\left(\mathrm{Ph}\left(\mathrm{CH}_{2}\right)_{3} \mathrm{OH}\right)_{2}$ content.

Table 8. Characteristic values for G'-G' crossover in the master curves $\left(T_{\text {ref }}=80^{\circ} \mathrm{C}\right)$ of $P U(U) S$ based on varying $\mathrm{S}_{2}\left(\mathrm{Ph}\left(\mathrm{CH}_{2}\right)_{3} \mathrm{OH}\right)_{2}$ content.

\begin{tabular}{c|c|c|c}
\hline Run & Sample & $\omega_{d}\left(\right.$ rad.s $\left.^{-1}\right)$ & $\tau_{d}$ \\
\hline $\mathbf{4}$ & PUU-6D-0.33S & 0.0013 & $1.5 \mathrm{~h}$ \\
\hline $\mathbf{8}$ & PU-6D-0.33S & 784 & $0.008 \mathrm{~s}$ \\
$\mathbf{9}$ & PU-6D-0.44S & 240 & $0.026 \mathrm{~s}$ \\
10 & PU-6D-0.53S & 12 & $0.524 \mathrm{~s}$ \\
\hline 11 & PUU-6D-0.53S-MIXED & $0.1-0.001$ & $1 \mathrm{~min}-2 \mathrm{~h}$ \\
\hline
\end{tabular}

Scratch closure of the PUs and the mixed disulfide PUU was optically monitored at $80^{\circ} \mathrm{C}$ (Figure 16). It can be seen that the time needed for scratch closure $\left(t_{\text {scratch }}\right)$ increases with the relaxation time, but as in the case of the PUUs of Table 1 , in all cases $t_{\text {scratch }}>\tau_{d}$, because as explained above, creep deformation of the polymer is needed for scratch closure. The scratch closure times correlate quite well with the storage modulus ( $\left.E^{\prime}\right)$ at the temperature at which the test was carried out $\left(80^{\circ} \mathrm{C}\right)$ as can be observed in Figure $17 . \mathrm{In}$ order to construct this figure, the values of the storage modulus at $80^{\circ} \mathrm{C}$ were obtained by extrapolating the data in Figures 5,6 and 13; and the values of $t_{\text {scratch }}$ were roughly estimated from Figures 8,9 and 16. Although the use of the approximate interrelations among viscoelastic functions, which allows estimating creep from dynamic viscoelastic results, is out of the scope of this work, it is known that E' is inversely proportional to the creep compliance function $\mathrm{D}(\mathrm{t}){ }^{52}$ Therefore, increasing the storage modulus $\mathrm{E}^{\prime}$ should give rise to a lower compliance or deformation capacity, which leads to higher scratch closure times. 
From a practical point of view, short times for scratch closure at the healing temperature and good mechanical properties at the service temperature (for most cases room temperature) are required. Therefore, Figure 18 compares the Young's modulus $(E)$ determined in the tensile tests carried out at room temperature with $t_{\text {scratch }}$ at $80^{\circ} \mathrm{C}$ for all of the synthesized polymers. It can be seen that for the same $t_{\text {scratch }}$, the PUs present much better mechanical properties than the PUUs, with the additional advantage of having a higher concentration of disulfide groups. The reason for the high Young's modulus of the PUs at room temperature is that the absence of the strong hydrogen bonds provided by the urea groups is compensated by the reduction of the soft PolyTHF content. On the other hand, at the healing temperature, the alkyl moiety of the disulfide unit of the PUs allows a certain mobility of the hard segments lowering the storage modulus below that of the PUUs. These results highlight the importance of the polymer microstructure and the opportunities of playing not only with the dynamic moieties, but also with the polymer architecture to develop attractive self-healing materials.

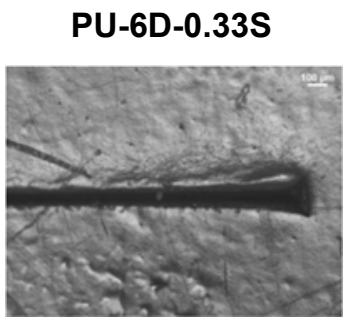

$\downarrow 1 \mathrm{~h}$

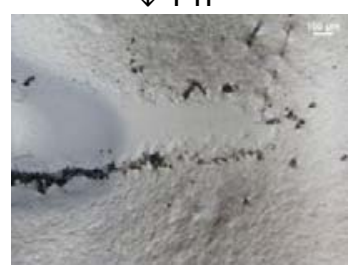

PU-6D-0.44S

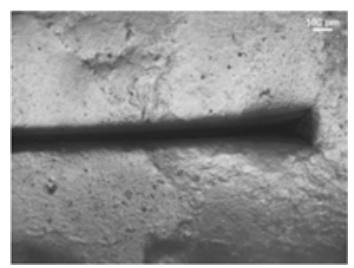

$\downarrow 1 \mathrm{~h}$

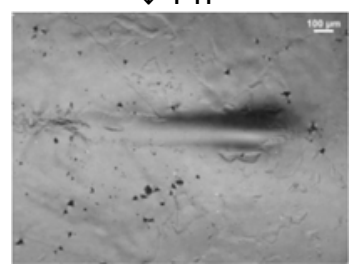

PU-6D-0.53S

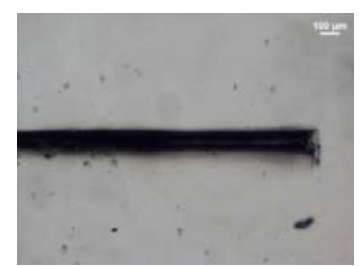

$\downarrow 2 \mathrm{~h}$

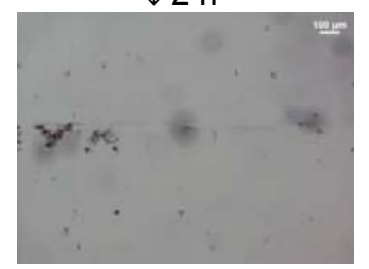

PUU-6D-0.53S-MIXED

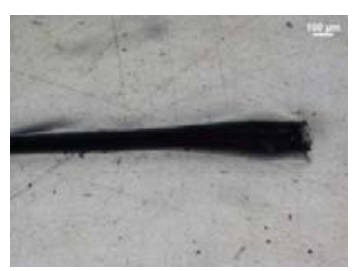

$\downarrow 7 \mathrm{~d}$

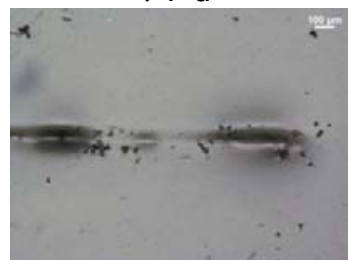

Figure 16. Scratch closure at $80^{\circ} \mathrm{C}$ of $\mathrm{PU}(\mathrm{U})$ s based on varying amount of $\mathrm{S}_{2}\left(\mathrm{Ph}\left(\mathrm{CH}_{2}\right)_{3} \mathrm{OH}\right)_{2}$.
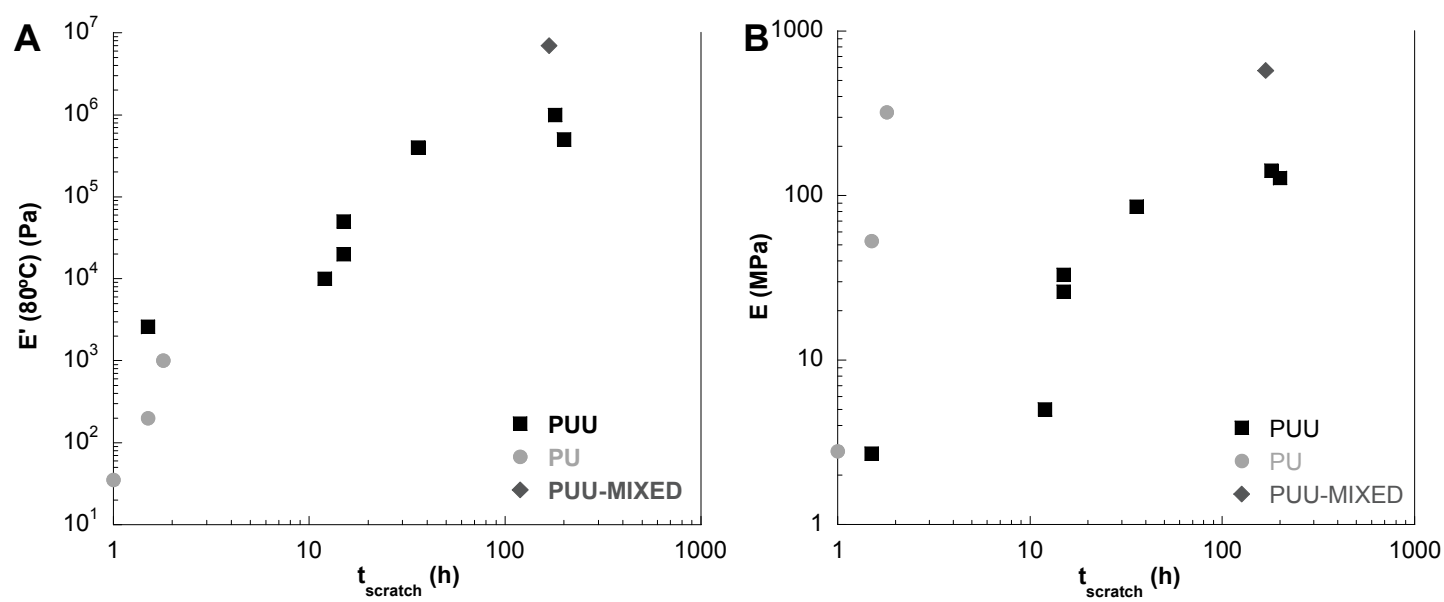

Figure 17. Relationship between the storage modulus $E^{\prime}\left(T=80^{\circ} \mathrm{C}\right)(\mathrm{A})$ or the Young's modulus $E(R T)(B)$ and the time for scratch closure $t_{\text {scratch }}\left(T=80^{\circ} \mathrm{C}\right)$ for all $P U(U) s$. 
The combination of good mechanical properties at the service temperature with considerable mobility at easily reachable healing temperatures marks a significant improvement on previous self-healing polyurethanes and potentially allows the production of strong yet healable coatings systems. Interestingly, to best of our knowledge, the strongest self-healing PU elastomers based on aromatic disulfides described in literature so far were developed by Kim et al., ${ }^{35}$ presenting stress-strain curves with a maximum tensile strength of $6.8 \mathrm{MPa}$ at a strain rate of $100 \mathrm{~mm} \cdot \mathrm{min}^{-1}$. With this in mind, the attractive and unique mechanical properties of the developed $P U(U)$ s are obvious as PU-6D-0.53 has a yield strength of $10 \mathrm{MPa}$ and PUU-6D-0.53S-MIXED has an ultimate tensile strength of $23 \mathrm{MPa}$ both at a strain rate of $25 \mathrm{~mm} . \mathrm{min}^{-1}$, whilst still demonstrating complete scratch closure at slightly elevated temperatures. It seems clear from the presented results that a material that has the mechanical strength required for high-end applications cannot be expected to undergo self-healing at the room temperature. If this were the case, the short relaxation time of the material would inevitably lead to the material undergoing creep and therefore puts a significant restriction on its practical utility. However, through careful tuning of rheological behaviour of the polymer through designed synthesis, it appears possible for a material to show a marked transition from a strong material at room temperature, to a softer, healable material at elevated temperatures. This requires an interplay of chemistry and rheology which should be the focus of future research.

\section{Conclusions}

In summary, a series of waterborne $\mathrm{PU}(\mathrm{U})$ dispersions were synthesized with varying amount of hard monomers, namely DMPA and aromatic disulfide compounds, incorporated into the polymer backbone. By increasing the DMPA content, it was possible to obtain higher mechanical properties leading to ultimate tensile strengths up to $17 \mathrm{MPa}$, however, this limited the mobility of the polymer which could be observed in scratch closure and which was confirmed by longer relaxation times in frequency sweep measurements. Furthermore, this study demonstrated that, contrary to the intuition of a chemist, an increasing amount of self-healing agent does not necessarily offer a higher mobility of the material which is crucial to obtain self-healing. Since the incorporation of both bis(4-aminophenyl)- and bis(4-hydroxyphenyl)disulfide into the $\mathrm{PU}(\mathrm{U})$ backbone was restricted due to limitations towards solubility, reactivity and mobility, the more flexible bis[4-(3'-hydroxypropoxy)phenyl]disulfide was introduced as a modified aromatic disulfide in order to obtain waterborne PU materials. In this way, it was possible to increase the amount self-healing agent and thus that of the disulfide bonds present in the polymer backbone, without compromising the mechanical properties of the materials, which reached ultimate tensile strengths in the range of 10 to $23 \mathrm{MPa}$, at the service temperature and providing good mobility at the healing temperature. This proved the fact that next to the presence of dynamic bonds or intermolecular interactions, the polymer architecture and in this case the structure of the introduced disulfide compound plays a crucial role in the mobility and consequently self-healing ability of the material. Further optimization of the developed waterborne $\mathrm{PU}(\mathrm{U})$ materials, incorporating the modified aromatic disulfide compound, may therefore lead to more efficient self-healing polymers which can serve in applications requiring higher mechanical strength and will be the focus of future studies. 


\section{Competing interests}

There are no competing interests to declare. Declarations of interest: none.

\section{Acknowledgements}

The European Union's Horizon 2020 research and innovation programme is accredited for the financial support through Project TRACKWAY-ITN 642514 under the Marie Sklodowska-Curie grant agreement. N.B. acknowledges the financial support obtained through the Post-Doctoral fellowship Juan de la Cierva - Incorporación (IJCl-2016-28442), from the Ministry of Economy and Competitiveness of Spain.

\section{Bibliographic references and notes}

1 S. S. Lucas, M. von Tapavicza, A. M. Schmidt, J. Bertling and A. Nellesen, J. Intell. Mater. Syst. Struct., 2016, 27, 2577-2598.

2 S. Bode, M. Enke, M. Hernandez, R. K. Bose, A. M. Grande, S. van der Zwaag, U. S. Schubert, S. J. Garcia and M. D. Hager, in Self-healing materials, eds. M. D. Hager, S. van der Zwaag and U. S. Schubert, Springer, 2016, vol. 273, pp. 113142.

3 W. H. Binder, Self-healing polymers, Wiley-VCH, 2013.

$4 \quad$ P. Zhang and G. Li, Prog. Polym. Sci., 2016, 57, 32-63.

5 B. J. Blaiszik, S. L. B. Kramer, S. C. Olugebefola, J. S. Moore, N. R. Sottos and S. R. White, Annu. Rev. Mater. Res., 2010, 40, 179-211.

6 Y. Yang and M. W. Urban, Chem. Soc. Rev., 2013, 42, 7446-7467.

7 M. D. Hager, P. Greil, C. Leyens, S. van der Zwaag and U. S. Schubert, Selfhealing materials, Springer, 2016.

8 J. A. Syrett, C. R. Becer and D. M. Haddleton, Polym. Chem., 2010, 1, 978-987.

9 Y. Yang, X. Ding and M. W. Urban, Prog. Polym. Sci., 2015, 49-50.

10 M. Qiu Zhang and M. Zhi Rong, Self-Healing Polymers and Polymer Composites, Wiley, 2011.

11 S. Billiet, X. K. D. Hillewaere, R. F. A. Teixeira and F. E. Du Prez, Macromol. Rapid Commun., 2013, 34, 290-309.

12 H. W. Engels, H. G. Pirkl, R. Albers, R. W. Albach, J. Krause, A. Hoffmann, H. Casselmann and J. Dormish, Angew. Chemie - Int. Ed., 2013, 52.

13 Y. Wei, X. Du, X. Ma, K. Zhao, S. Zhang and Y. Bai, Polym. Bull., 2017, 74, 39073922.

14 Y. Fang, X. Du, Z. Du, H. Wang and X. Cheng, J. Mater. Chem. A, 2017, 5, 80108017.

15 W. Denissen, M. Droesbeke, R. Nicolaÿ, L. Leibler, J. M. Winne and F. E. Du Prez, Nat. Commun., 2017, 8, 14857.

16 A. Feula, A. Pethybridge, I. Giannakopoulos, X. Tang, A. Chippindale, C. R. Siviour, C. P. Buckley, I. W. Hamley and W. Hayes, Macromolecules, 2015, 48.

17 Y. Xiao, H. Huang and X. Peng, RSC Adv., 2017, 7, 20093-20100.

18 M. Krogsgaard, M. A. Behrens, J. S. Pedersen and H. Birkedal, Biomacromolecules, 2013, 14, 297-301.

19 X. Yang, H. Yu, L. Wang, R. Tong, M. Akram, Y. Chen and X. Zhai, Soft Matter, 2015, 11, 1242-1252.

20 S. Nevejans, N. Ballard, J. I. Miranda, B. Reck and J. M. Asua, Phys. Chem. Chem. Phys., 2016, 18, 27577-27583.

21 J. Canadell, H. Goossens and B. Klumperman, Macromolecules, 2011, 44, 2536- 
2541.

22 M. Pepels, I. Filot, B. Klumperman and H. Goossens, Polym. Chem., 2013, 4, 4955.

Y. Xu and D. Chen, Macromol. Chem. Phys., 2016, 217, 1191-1196.

W. M. Xu, M. Z. Rong and M. Q. Zhang, J. Mater. Chem. A, 2016, 4, 10683-10690.

L. Zhang, L. Chen and S. J. Rowan, Macromol. Chem. Phys., 2017, 218, 1600320.

T. Wan and D. Chen, J. Mater. Sci., 2017, 52, 197-207.

27 X. Wu, J. Li, G. Li, L. Ling, G. Zhang, R. Sun and C. Wong, J. Appl. Polym. Sci., $2018,135,46532$.

28 X. Jian, Y. Hu, W. Zhou and L. Xiao, Polym. Adv. Technol., 2018, 29, 463-469.

29 A. Rekondo, R. Martin, A. Ruiz de Luzuriaga, G. Cabañero, H. J. Grande and I. Odriozola, Mater. Horizons, 2014, 1, 237-240.

30 J. M. Matxain, J. M. Asua and F. Ruipérez, Phys. Chem. Chem. Phys., 2016, 18, 1758-1770.

31 R. H. Aguirresarobe, L. Martin, M. J. Fernandez-Berridi and L. Irusta, EXPRESS Polym. Lett., 2017, 11, 266-277.

32 M. Yarmohammadi, M. Shahidzadeh and B. Ramezanzadeh, Prog. Org. Coatings, 2018, 121, 45-52.

33 M. Yarmohammadi and M. Shahidzadeh, J. Appl. Polym. Sci., 2018, 135, 46309.

34 Y. Yang, X. Lu and W. Wang, Mater. Des., 2017, 127, 30-36.

35 S.-M. Kim, H. Jeon, S.-H. Shin, S.-A. Park, J. Jegal, S. Y. Hwang, D. X. Oh and J. Park, Adv. Mater., 2018, 30, 1705145.

36 J. Dahlke, S. Zechel, M. D. Hager and U. S. Schubert, Adv. Mater. Interfaces, 2018, $1800051,1-14$.

37 S. J. Garcia, Eur. Polym. J., 2014, 53, 118-125.

38 S. J. García, H. R. Fischer and S. Van Der Zwaag, Prog. Org. Coatings, 2011, 72, 211-221.

39 P. H. Markusch, J. W. Rosthauser, M. C. Beatty, Mobay Corp, US4501852A, 1985.

40 W. Temme, R. Bergs, H. Haberle, A. Maier, Construction Research and Technology $\mathrm{GmbH}, \mathrm{US20020004553A1,2002.}$

41 D. Schütze, G. Kurek, T. Rische, J. Urban, T. Hassel, Covestro Deutschland AG, US6642303B2, 2003.

42 H. Haberle, W. Temme, R. Bergs, N. Steidl, A. Maier, Conica Technik AG Construction Research and Technology GmbH SKW Bauwerkstoffe Deutschland GmbH, US20030088045A1, 2003.

43 T. Ohishi, Y. Iki, K. Imato, Y. Higaki, A. Takahara and H. Otsuka, Chem. Lett., 2013, 42, 1346-1348.

44 S. Hamzehlou, N. Ballard, P. Carretero, M. Paulis, J. M. Asua, Y. Reyes and J. R. Leiza, Polymer, 2014, 55, 4801-4811.

45 S. Mehravar, N. Ballard, A. Agirre, R. Tomovska and J. M. Asua, Eur. Polym. J., 2017, 87, 300-307.

46 J. Y. Jho and A. F. Yee, Macromolecules, 1991, 24, 1905-1913.

47 L. Delbreilh, A. Bernès and C. Lacabanne, Int. J. Polym. Anal. Charact., 2005, 10, 41-56.

48 E. B. Stukalin, L. H. Cai, N. A. Kumar, L. Leibler and M. Rubinstein, Macromolecules, 2013, 46, 7525-7541.

49 S. Chen, N. Mahmood, M. Beiner and W. H. Binder, Angew. Chemie Int. Ed., 2015, 54, 10188-10192.

50 S. Hackelbusch, T. Rossow, P. van Assenbergh and S. Seiffert, Macromolecules, 2013, 46, 6273-6286.

51 S. Bode, M. Enke, R. K. Bose, F. H. Schacher, S. J. Garcia, S. van der Zwaag, M.

D. Hager and U. S. Schubert, J. Mater. Chem. A, 2015, 3, 22145-22153. 
52 J. D. Ferry, Viscoelastic Properties of Polymers, Wiley, 1980.

53 S. Seiffert and J. Sprakel, Chem. Soc. Rev., 2012, 41, 909-930.

54 M. Müller, U. Seidel and R. Stadler, Polymer, 1995, 36, 3143-3150.

55 F. J. Stadler, W. Pyckhout-Hintzen, J.-M. Schumers, C.-A. Fustin, J.-F. Gohy and C. Bailly, Macromolecules, 2009, 42, 6181-6192.

56 K. E. Feldman, M. J. Kade, E. W. Meijer, C. J. Hawker and E. J. Kramer, Macromolecules, 2009, 42, 9072-9081.

57 X. Callies, C. Fonteneau, C. Véchambre, S. Pensec, J.-M. Chenal, L. Chazeau, L. Bouteiller, G. Ducouret and C. Creton, Polymer, 2015, 69, 233-240.

58 M. Abdolah Zadeh, A. M. Grande, S. van der Zwaag and S. J. Garcia, RSC Adv., 2016, 6, 91806-91814.

59 A. M. Grande, J. C. Bijleveld, S. J. Garcia and S. van der Zwaag, Polymer, 2016, 96, 26-34.

60 R. K. Bose, M. Enke, A. M. Grande, S. Zechel, F. H. Schacher, M. D. Hager, S. J. Garcia, U. S. Schubert and S. van der Zwaag, Eur. Polym. J., 2017, 93, 417-427.

61 A. M. Grande, R. Martin, I. Odriozola, S. van der Zwaag and S. J. Garcia, Eur. Polym. J., 2017, 97, 120-128.

62 S. Trinkle, P. Walter and C. Friedrich, Rheol. Acta, 2002, 41, 103-113.

63 H. F. Mark, Encyclopedia of Polymer Science and Technology, Concise, Wiley, 2013.

64 E. Delebecq, J.-P. Pascault, B. Boutevin and F. Ganachaud, Chem. Rev., 2013, 113, 80-118. 